\title{
Long Range Prediction and the Stratosphere
}

2

3 Adam A. Scaife ${ }^{1,2}$, Mark P. Baldwin ${ }^{3}$, Amy H. Butler ${ }^{4}$, Andrew J. Charlton-Perez ${ }^{5}$, Daniela 4 I.V. Domeisen ${ }^{6,7}$, Chaim I. Garfinkel ${ }^{8}$, Steven C. Hardiman ${ }^{1}$, Peter Haynes ${ }^{9}$, Alexey Yu 5 Karpechko $^{10}$, Eun-Pa Lim ${ }^{11}$, Shunsuke Noguchi ${ }^{12,13}$, Judith Perlwitz ${ }^{14}$, Lorenzo Polvani ${ }^{15,16}$, 6 Jadwiga H. Richter ${ }^{17}$, John Scinocca ${ }^{18}$, Michael Sigmond ${ }^{18}$, Theodore G. Shepherd ${ }^{5}$, Seok7 Woo Son ${ }^{19}$, and David W.J. Thompson ${ }^{20}$.

$8 \quad{ }^{1}$ Met Office Hadley Centre for Climate Prediction and Research, Exeter, U.K.

$9 \quad{ }^{2}$ College of Engineering, Mathematics and Physical Sciences, Exeter University, Exeter, U.K.

$10{ }^{3}$ Department of Mathematics and Global Systems Institute, University of Exeter, Exeter, U.K.

${ }^{4}$ NOAA Chemical Sciences Laboratory (CSL), Boulder, CO, USA.

${ }^{5}$ Department of Meteorology, University of Reading, Reading, U.K.

${ }^{6}$ ETH Zurich, Institute for Atmospheric and Climate Science, Zurich, Switzerland.

${ }^{7}$ University of Lausanne, Institute of Earth Surface Dynamics, Lausanne, Switzerland

${ }^{8}$ Fredy and Nadine Herrmann Institute of Earth Sciences, Hebrew University of Jerusalem, Jerusalem, Israel

${ }^{9}$ Department of Applied Mathematics and Theoretical Physics, University of Cambridge, Cambridge, UK

${ }^{10}$ Finnish Meteorological Institute, Helsinki, Finland

${ }^{11}$ Bureau of Meteorology, Melbourne, Australia

${ }^{12}$ Research Center for Environmental Modeling and Application, Japan Agency for Marine-Earth Science and Technology (JAMSTEC), Yokohama, Japan

${ }^{13}$ Meteorological Research Institute, Japan Meteorological Agency, Tsukuba, Japan

${ }^{14}$ NOAA Physical Sciences Laboratory (PSL), Boulder, CO, USA

${ }^{15}$ Columbia University, Department of Applied Physics and Applied Mathematics, U.S.A.

${ }^{16}$ Department of Earth and Environmental Sciences, New York City, NY, U.S.A.

${ }^{17}$ Climate and Global Dynamics Laboratory, National Center for Atmospheric Research, Boulder, Colorado, U.S.A.

${ }^{18}$ Canadian Centre for Climate Modelling and Analysis, Environment and Climate Change Canada, Victoria, BC, Canada

${ }^{19}$ School of Earth and Environmental Sciences, Seoul National University, Seoul, Republic of Korea

${ }^{20}$ Department of Atmospheric Science, Colorado State University, Fort Collins, Colorado, U.S.A.

Correspondence to: $\quad$ Adam A. Scaife (adam.scaife@metoffice.gov.uk) 
Abstract. Over recent years there have been parallel advances in the development of stratosphere resolving numerical models, our understanding of stratosphere-troposphere interaction and the extension of long-range forecasts to explicitly include the stratosphere. These advances are now allowing new and improved capability in long range prediction. We present an overview of this development and show how the inclusion of the stratosphere in forecast systems aids monthly, seasonal and decadal climate predictions. We end with an outlook towards the future of climate forecasts and identify areas for improvement that could further benefit these rapidly evolving predictions.

\section{Introduction}

The climate system contains significant unpredictable variance and - for daily weather fluctuations at least - it is thought to have a deterministic predictability horizon of around two weeks due to the sensitivity of the evolution of the atmospheric state to small errors in initial conditions (Lorenz 1969) the so-called 'butterfly effect'. Recent estimates (Leung et al., 2020; Domeisen et al., 2018) as well as tests of the predictability of midlatitude daily weather using the latest global prediction models (Zhang et al., 2019; Son et al., 2020) produce similar estimates for this predictability limit. However, this does not preclude skilful forecasts of the statistics (most notably the average) of conditions at long range beyond this timescale (e.g. Shukla 1981). This predictability owes its existence to slowly varying predictable components of the climate system in the ocean, and in some cases the atmosphere, as well as externally forced changes such as volcanic or solar variability effects (e.g. Kushnir et al., 2019). Some of the more prominent examples of stratospheric variability such as sudden stratospheric warmings and their interaction with the troposphere (Baldwin et al., 2021) and the quasi-biennial oscillation and its associated teleconnections (Scaife et al., 2014a) have been shown to fall into this predictable category, thereby providing relatively slowly varying conditions to guide the turbulent troposphere and hence provide long range predictability of conditions beyond the two-week limit.

The extension of long-range prediction systems to explicitly include representation of the stratosphere follows many years of development of stratosphere resolving general circulation models (GCMs). By the late $20^{\text {th }}$ century many leading centres for climate research had started to include the stratosphere in versions of their GCMs (Pawson et al., 2000; Gerber et al., 2012). Much of the early model development was motivated by the discovery of the ozone hole in the 1980s (Farman et al., 1985) and the need for simulations of ozone depletion and potential recovery of the ozone hole following the 1987 Montreal Protocol, which required atmospheric models that represented both the atmospheric dynamics and chemistry of stratospheric ozone depletion (Molina and Rowland 1974; Crutzen 1974). In most cases this was achieved by adding further quasi-horizontal layers to the domain of existing climate models to extend their representation of the atmosphere to the stratopause or beyond (e.g. Rind et al 1988; Beagley et al., 1997; Swinbank et al., 1998; Sassi et al., 2002), while also incorporating key radiative (e.g. Fels et al., 1985), chemical (e.g. Steil et al., 1998) and dynamical (e.g. Scaife et al., 2000) processes.

The early development of so called 'high top' climate models, which represent the whole depth of the stratosphere, in general preceded the discovery of the main body of evidence that the variability of the stratosphere is not only affected by, but also interacts with the lower atmosphere and surface climate. Pioneering early studies suggested that the stratosphere might have direct effects on the troposphere and surface climate (e.g. Labitzke 1965; Boville 1984; Kodera et al., 1990, 1995; Haynes et al., 1991; Perlwitz and Graf 1995). In subsequent years, as reliable observational records lengthened and large enough samples of stratospheric variability were amassed it was unequivocally demonstrated that stratospheric variability precedes important tropospheric changes in the extratropics (Baldwin and Dunkerton 1999, 2001). There was debate about causality and whether the stratosphere really does affect the atmosphere below (e.g. Plumb and Semeniuk 2003). However, experiments where the stratosphere is perturbed in numerical models show changes in surface climate and reproduce similar patterns of response at the surface to those found in real world observations (e.g. Polvani and Kushner 
2002; Norton et al., 2003; Scaife et al., 2006; Joshi et al., 2006; Scaife and Knight 2008; Hitchcock and Haynes 2016, White et al., 2020). These involve changes to planetary scale waves and also baroclinic eddies in the troposphere that are consistent with changes in baroclinicity near the tropopause (Kushner and Polvani 2004; Song and Robinson 2004; Wittman et al., 2004, 2007; Scaife et al., 2012; Domeisen et al., 2013; Hitchcock and Simpson 2014; White et al., 2020). Importantly, as we discuss below, the same mechanisms also appear to be at work across a broad range of timescales (Kidston et al., 2015).

In recent years, motivated by the evidence of surface effects of stratospheric variability in the midlatitudes, the high-top model configurations used for stratospheric research were incorporated into leading long-range prediction systems. This was initially done in test experiments, some of which were internationally coordinated (e.g. Butler et al., 2016; Tompkins et al., 2017). However, a growing number of operational systems are now producing ensembles of predictions at lead times of months or years with coupled ocean-atmosphere models that extend to the stratopause or beyond; for example at Environment Canada (Merryfield et al., 2013), the Met Office in the UK (MacLachlan et al., 2014), the German Weather Service DWD (Baehr et al., 2015), the Japan Meteorological Agency (Takaya et al., 2017) and the European Centre for Medium Range Weather Forecasts (Johnson et al., 2019). In the following sections we document the emerging impacts and benefits of this new capability for surface climate predictions at monthly, seasonal, and annual to decadal lead times.

\section{The stratosphere and monthly prediction}

The best-established phenomenon that gives rise to predictability of surface climate from the stratosphere are the tropospheric circulation changes that follow strong and weak conditions in the stratospheric polar vortex (Baldwin and Dunkerton 1999, 2001). For example, weak vortex conditions such as those found in a sudden stratospheric warming (SSW, Baldwin et al., 2021) are typically followed by a weakening and southward shift of the tropospheric mid-latitude jet stream (see e.g. Kidston et al., 2015 and references therein) and thus the negative polarity of the North Atlantic Oscillation (NAO), Arctic Oscillation (AO) and Northern Annular Mode (NAM). These fluctuations also show a tendency to vacillate between strong westerly and weak (SSW) states on subseasonal timescales (Kuroda and Kodera 2001; Hardiman et al., 2020a). The changes in the troposphere persist roughly as long as those in the lower stratosphere, and last for around two months (Baldwin and Dunkerton 2001; Baldwin et al., 2003; Hitchcock et al., 2013; Son et al., 2020; Domeisen 2019). The impacts on surface climate also affect the frequency of extremes of temperature and rainfall (Scaife et al., 2008; King et al., 2019; Cai et al., 2016; Domeisen et al., 2020b).

Although major SSW events, involving a complete reversal of the zonal flow in the mid stratosphere, are rare in the southern hemisphere (Wang et al., 2020; Jucker et al., 2021), variations of the Antarctic polar vortex are likewise followed by similar signatures in the underlying tropospheric flow, in this case via the Southern Annular Mode (SAM). Weakening of the vortex is typically followed by a negative shift in the SAM and associated changes in rainfall and near surface temperature (Thompson et al., 2005; Lim E. et al., 2018, 2019, 2021). These changes in Southern Hemisphere circulation typically take longer to reach the surface than their Northern Hemisphere counterparts (Graverson and Christiansen 2003), perhaps due to the stronger stratospheric polar vortex and weaker wave driving in the southern hemisphere, but they are nonetheless better predicted by improving stratospheric resolution of forecast models (Roff et al., 2011). The timescale of weeks for the predictability of sudden warmings is limited by the predictability of weather patterns in the troposphere which might trigger SSW events (e.g. Mukougawa et al., 2005; Taguchi 2016; Garfinkel and Schwarz 2017; Jucker and Reichler 2018; Lee et al., 2020a). However, if we add this timescale to the timescale of a month or more for the persistence of lower stratospheric anomalies and their surface effects (e.g. Baldwin et al., 2003; Butler et al., 2019), we arrive at the conclusion that on these occasions at least, initial conditions in the 
atmosphere can provide predictability well beyond the usual two-week horizon for daily weather in either hemisphere.

Predictability of the atmosphere at monthly lead times is also known to originate in part from the Madden Julian Oscillation (MJO) in the troposphere and its teleconnection to the extratropics (e.g. Vitart 2017). The circulation pattern associated with the MJO resembles a poleward and eastward propagating Rossby wave with centres of action over the Pacific and extending into the Atlantic sector where it also maps strongly onto the North Atlantic Oscillation. The lead time of around 10 days for the impact of a change in the MJO to appear in the extratropical flow (e.g. Cassou 2008; Lin et al., 2009) is also consistent with the timescale for poleward propagation of Rossby waves (e.g. Scaife et al., 2017). It turns out that this tropospheric MJO teleconnection on monthly timescales also interacts with the stratosphere (Garfinkel and Schwartz 2017). The MJO teleconnection to the North Pacific affects the region most strongly associated with tropospheric precursors to SSW events, and consistent with this, SSWs in the observational record have tended to follow certain MJO phases. The subsequent weak vortex anomaly then propagates down to the troposphere (Garfinkel et al 2012), where it may strengthen and prolong any existing negative NAO signal that is directly linked to the MJO via the troposphere (Schwartz and Garfinkel 2017, 2020; Barnes et al., 2019).

In addition to the interaction of the MJO with the extratropical stratosphere, a further, completely different link between the stratosphere and the MJO has recently been uncovered which modulates MJO amplitude and persistence in the troposphere via the phase of the Quasi-Biennial Oscillation (QBO) in the tropical lower stratosphere (Liu et al., 2014; Yoo and Son 2016; Martin et al., 2021). In this case, easterly phases of the QBO appear to energise the MJO compared to westerly QBO, likely due to changes in temperature and hence static stability close to the tropopause (Hendon and Abhik 2018; Martin et al., 2019) with a potential contribution of cloud-radiation feedbacks (Son et al., 2017, see Martin et al., 2021 for a review). This modulation of the MJO is in turn important for predictability as it gives rise to higher monthly prediction skill of the MJO and its surface teleconnections during the easterly phase of the QBO (Marshall et al., 2017; Abhik and Hendon 2019; Lim Y. et al., 2019).

Other mechanisms have also been found that can provide potentially predictable signals on the monthly timescale. The traditional view of stratosphere-troposphere interaction involves upward propagation of planetary scale Rossby waves (Charney and Drazin 1961), but this linear theory applies equally well to downward propagation. Harnik and Lindzen (2001) and Perlwitz and Harnik (2003) identified a possible source of downward propagating planetary waves in the form of reflecting surfaces in the winter stratosphere. Examples of specific reflection events, showing upwards and then downward propagation have since been observed (e.g. Kodera et al., 2008; Harnik 2009; Kodera and Mukougawa 2017; Mukougawa et al., 2017; Matthias and Kretschmer 2020). These results suggest that the details of the stratospheric circulation such as regions of negative vertical wind shear could be important for the formation of reflecting conditions (Perlwitz and Shaw 2013) and may yet provide a further mechanism by which the stratosphere can affect the troposphere (Domeisen et al., 2019; Butler et al., 2019).

Following studies demonstrating enhanced tropospheric predictability after SSW events in individual climate models (e.g. Kuroda 2008; Mukougawa et al 2009; Marshall and Scaife 2010; Sigmond et al 2013), subseasonal forecast systems which explicitly represent the stratosphere in the climate system were developed and implemented at operational prediction centres worldwide. It is often difficult to demonstrate significant increases in overall skill (e.g. Richter et al 2020a) but routinely produced ensembles of subseasonal predictions show that both stratospheric variability and its subsequent tropospheric signature are predictable at monthly lead times (Domeisen et al 2020a, 2020b). The strongest surface impacts occur if the polar vortex in the lower stratosphere is in a weakened state at the time of the SSW (Karpechko et al., 2017) and there appears to be a roughly linear relationship between the strength of these lower stratospheric anomalies and the tropospheric response (e.g. Runde 
et al., 2016; White et al., 2020 and see Baldwin et al., 2019 for a review). We should note however that there is no one-to-one correspondence between stratospheric variability and tropospheric events, and some prominent examples of sudden stratospheric warmings are followed by differing tropospheric anomalies (e.g. Charlton-Perez et al., 2018; Knight et al., 2020; Butler et al., 2020; Rao et al., 2020a). Nevertheless, the canonical response is seen in the majority $(\sim 70 \%)$ of cases and periods of intense wintertime stratospheric variability are important windows of opportunity to provide skilful monthly forecasts (Mariotti et al., 2020; Tripathi et al., 2015a).
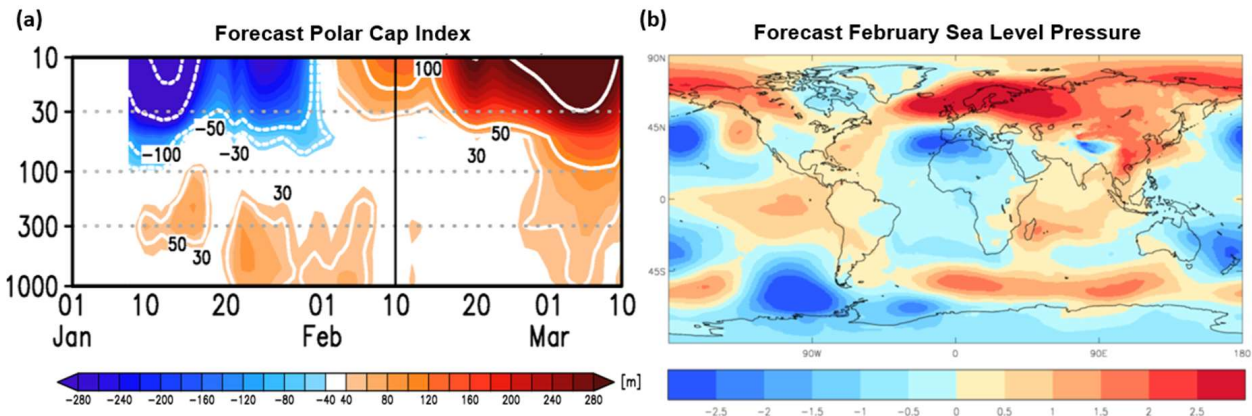

Figure 1: Monthly forecasts prior to the 2018 sudden stratospheric warming and severe cold event over northern Europe. Forecast Polar Cap Index (a) and February sea level pressure anomalies (b). Forecasts were initialised in January 2018 (initialisation dates: $8^{\text {th }}, 1^{\text {th }}$ and $22^{\text {nd }}$ ) using the Met Office Hadley Centre GloSea prediction system (MacLachlan et al., 2015). Sea level pressure is measured in hPa and Polar Cap Index is the geopotential height anomaly $(\mathrm{m})$ averaged over $65 \mathrm{~N}$ to the North Pole.

These forecast systems are now important tools for national meteorological and hydrological services to monitor impending stratospheric variability and associated surface impacts in real time. Recent extreme examples illustrate the importance of this activity. In February 2018 a major SSW occurred and was followed by a strong negative NAO-like pattern at the surface with easterly wind anomalies over Europe and multiple cold air outbreaks over the following weeks, including extreme snowfall across northern Europe (Figure 1, Karpechko et al., 2018; Knight et al., 2020; Rao et al., 2020a) and an abrupt end to Iberian drought in Southern Europe (Ayarzagueña et al., 2018). Studies of monthly ensemble predictions of this event with operational stratosphere resolving systems showed that the stratospheric event was predictable at least 2 weeks in advance (Figure 1) and that the ensemble forecasts indicated increased likelihood of cold surface conditions for several weeks after the event (Karpechko 2018; Butler et al., 2020; Statnaia et al., 2020; Rao et al., 2020a). Again, as in the analysis of previous events, there was also a strong association with the MJO entering Phase 7 with increased convection in the West Pacific (cf. Garfinkel and Schwartz 2017) in the 2018 event. Finally, we should also note that cases of monthly forecasts where the stratosphere plays an important role are not restricted to winters with sudden stratospheric warmings and periods when the stratospheric polar vortex is above normal strength also provide opportunities for skilful monthly forecasts (Tripathi et al., 2015b; Scaife et al., 2016). In this case an opposite but symmetric surface response results, with strong positive NAO. A very recent example occurred in February 2020, when, following an extremely strong polar vortex (Hardiman et al., 2020b; Lee et al., 2020b; Lawrence et al., 2020; Rao et al., 2021a), the tropospheric jet in the Atlantic sector strengthened, and the associated increased storminess and rainfall in this case resulted in UK monthly rainfall reaching a new record high (Davies et al., 2021).

\section{The stratosphere and seasonal prediction}


Prior to the advent of dynamical forecast systems which explicitly represent the stratosphere, seasonal forecasts using empirical relationships and statistical methods were proposed. These relied on the prior state of the polar vortex and other predictable factors such as the QBO that are known to have links to surface climate (Thompson et al., 2002; Charlton et al., 2003; Christiansen et al., 2005; Boer and Hamilton 2008). In some cases they indicated additional predictability that was absent in existing operational forecast systems, providing further evidence of predictability involving the stratosphere and further motivating the extension of dynamical forecast systems to properly represent the stratosphere. Similar empirical forecast studies continue, and although they cannot provide evidence of predictability that is as strong as from forecasts using GCMs based on fundamental physical principles, they continue to be useful to indicate sources of predictability that need to be properly represented in comprehensive forecast systems (e.g. Folland et al., 2012; Wang et al., 2017; Hall et al., 2017; Byrne and Shepherd 2018).

Following the introduction of dynamical seasonal forecast systems with a good representation of the stratosphere, clear links between successful seasonal prediction of the North Atlantic Oscillation, the closely related Arctic Oscillation and the state of the stratospheric polar vortex have been identified in forecast output (e.g. Scaife et al., 2014b; Stockdale et al., 2015; Jia et al., 2017; Byrne et al., 2019). Similar signals are also seen in the southern hemisphere in relation to predictability of the Southern Annular Mode (Seviour et al., 2014; Lim et al., 2021). Statistically significant increases in overall skill directly attributable to the inclusion of the stratosphere in prediction systems is sometimes difficult to demonstrate (e.g. Butler et al., 2016), especially given that other factors such as horizontal resolution and physical parametrizations are often simultaneously changed. Nevertheless, the body of evidence now weighs heavily in favour of predictability of the NAO and SAM from the stratospheric polar vortex and from analyses showing reduced surface prediction skill in the absence of stratospheric variability (e.g. Hardiman et al 2011; Sigmond et al., 2013; Scaife et al., 2016).

A second clear example of seasonal predictability originating in the stratosphere is the Quasi-Biennial Oscillation (QBO). The QBO has such inherently long timescales that it persists for several months in seasonal forecasts from initial atmospheric conditions alone and its regularity means that it can be predicted from simple composites of earlier cycles. Nevertheless, a growing number of numerical models used in seasonal forecast systems can now simulate and predict the oscillation within climate forecasts (Garfinkel et al., 2018; Richter et al., 2020b; Stockdale et al., 2021) with the aid of forcing from parametrized non-orographic gravity waves. A surface impact of the QBO is also well established and has stood the test of time since it was first identified in the 1970s (Ebdon 1975; Thompson et al., 2002; Anstey and Shepherd 2014; Gray et al 2018). Yet again this response projects closely onto the North Atlantic Oscillation (and hence the Arctic Oscillation/Northern Annular Mode) in the northern hemisphere, and the Southern Annular Mode in the SH. The favoured mechanism involves refraction of vertically propagating Rossby waves in the lower stratosphere (Holton and Tan 1980), although other pathways may also be involved (e.g. Inoue et al., 2011; Yamazaki et al., 2020; Rao et al., 2021b, 2021). The observed magnitude of the QBO teleconnection is also large enough to provide seasonal predictability of surface climate (Boer and Hamilton 2008) but its modelled amplitude at the surface appears to be under-represented in current operational prediction systems and models (Scaife et al., 2014b; Garfinkel et al., 2018; O’Reilly et al., 2019; Rao et al., 2020b; Anstey et al 2021).

In addition to the stratosphere acting as a source of predictability, other mechanisms by which the stratosphere plays a role in seasonal predictions involve a pathway for global scale teleconnections. These often originate in the tropics where the longer timescales of coupled ocean-atmosphere variability such as the El Niño Southern Oscillation (ENSO, L'Heureux et al 2020) provide a predictable source of low frequency variability. Effects on the extratropics can occur by tropical excitation of anomalous Rossby waves which propagate polewards but also upwards into the stratosphere, as in the case of ENSO (Manzini et al., 2006; Domeisen et al., 2019), giving two pathways for extratropical influence (Butler et al., 2014). These highly predictable tropical sources of climate variability alter the strength 
and position of the stratospheric polar vortex in the extratropics as well as the frequency of SSWs (Polvani et al., 2017) and these are followed by changes in the seasonal westerly jets in the troposphere and surface climate via the North Atlantic Oscillation (Ineson and Scaife 2009; Cagnazzo and Manzini 2009) or the Southern Annular Mode (Byrne et al., 2019). As might be expected, both the QBO and ENSO teleconnections are best represented in seasonal forecast systems which contain a well resolved stratosphere (Butler et al., 2016). We note that new examples of the stratosphere acting as a conduit for seasonal teleconnections are still being uncovered (Hurwitz et al., 2012, Woo et al., 2015). For example, the Indian Ocean Dipole (IOD) received little attention in this context until the recent record event of late 2019, when it appears to have driven an extreme winter strengthening of the northern hemisphere stratospheric polar vortex. This strengthening took many weeks to decay, giving rise to extreme yet highly predictable conditions in the stratosphere and around the Atlantic sector in late boreal winter (Hardiman et al., 2020b; Lee et al., 2020b). The same event was also implicated in extreme changes in the polar vortex and the near SSW in the southern hemisphere (Rao et al., 2020e); an event that itself likely helped to drive the extreme summer conditions and wildfires over Australia that year (Lim et al., 2021).

Apparent links between Arctic sea ice and seasonal winter climate in the mid latitudes have also been suggested to be mediated by the stratosphere, with increased Rossby wave activity and a weakening of the stratospheric polar vortex in response to reduced sea ice, especially in the Barents-Kara Sea (Jaiser et al., 2013; Kim et al. 2014; King et al., 2016; Kretschmer et al., 2016). Some studies also reproduced surface signals in response to sea ice anomalies in seasonal forecasts of particular years that are in apparent agreement with observational estimates (e.g. Balmaseda et al., 2010; Orsolini et al., 2012). However, recent updates to observational records show weakening of these apparent effects (Blackport and Screen 2020) and significant non-stationarity (Kolstad and Screen 2019). Subsequent modelling studies with larger samples of simulations have provided mixed results (Zhang et al 2018; Dai and Song 2020; Smith et al 2021) and some argued that the atmospheric response to sea ice is weak and that while the sensitivity to Barents-Kara sea ice may be stronger, the stratospheric response in particular is highly variable (McKenna et al 2017). While there may well be a longer-term effect via the stratosphere from sea ice decline (Sun et al., 2015; Screen and Blackport 2019; Kretschmer et al., 2020), sensitivity of the response to the background state complicates the issue (Labe et al., 2019; Smith et al 2017), as do possible confounding influences from the tropics (Warner et al 2020) and to date there is no clear consensus for strong enough year to year effects to provide significant seasonal predictability.

Other proposed teleconnections acting via the stratosphere have been found in observations but remain to be confirmed with successful reproduction in physically based climate models. A prominent example involves a proposed link between Eurasian snow amounts and the stratosphere, followed by a return influence on the NAO and surface climate. In this case, enhanced snow cover or depth is associated with high pressure over north Eurasia, an increase in the flux of Rossby wave activity into the stratosphere and a subsequent weakening of the stratospheric polar vortex, followed by the expected negative shift in the NAO and AO (Cohen and Entekhabi; 1999, Cohen and Jones 2011; Cohen et al., 2014; Furtado et al., 2015). However, the strength of this link in climate models and seasonal predictions is modest (Fletcher et al., 2009; Riddle et al., 2013; Tyrrell et al., 2018, 2019) and does not agree with apparent links to the AO in observations (Kretschmer et al., 2016; Garfinkel et al., 2020) even when model mean state biases are corrected (Tyrrell et al., 2020). It has also been suggested that teleconnections to snow are non-stationary or non-causal and there is continued debate about its longterm robustness (Peings et al., 2013; Henderson et al., 2018).

In summary, a number of mechanisms by which the stratosphere acts to provide seasonal predictability either by acting directly as a source of predictable variability (e.g. the QBO, SSWs), or as a conduit for teleconnections (e.g. ENSO, MJO, IOD) have now been established in observations and have been confirmed using climate model simulations based on first principles. These operate in seasonal forecast systems, albeit with remaining errors such as the weakness of the QBO connection to surface climate. 
Meanwhile, other mechanisms involving the stratosphere (for example the response to snow cover variations) have been proposed based on apparent observed relationships, but until we have agreement between these observations and theory (model simulations), scientists remain sceptical of whether they represent actual sources of seasonal predictability and these topics remain topics of current research.

\section{The stratosphere and annual to decadal prediction}

In recent years, initialised predictions on longer timescales were developed on the premise of multiyear memory in the ocean (e.g. Smith et al 2007), and following the development pathway mapped out by seasonal forecasts in the past, these are now being run operationally to produce real time multi-model forecasts (Smith et al., 2013). Kushnir et al., (2019) mapped out this operational development of annual to decadal predictions and highlighted a number of sources of predictability, some of which involve the stratosphere (Figure 2), but not all of which are fully represented in climate prediction systems.

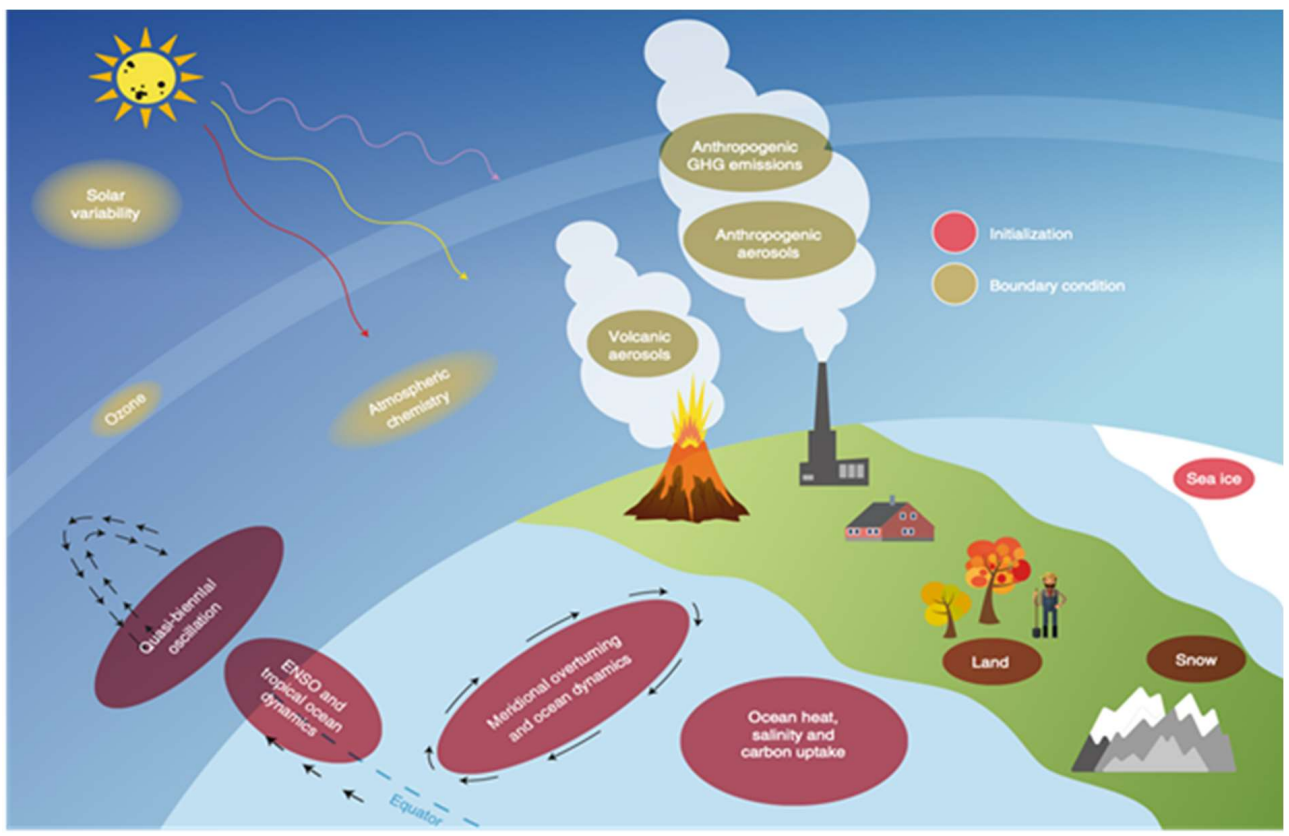

Figure 2. Sources of annual to decadal predictability, some of which involve the stratosphere through the response to external forcing, internal atmospheric dynamics, or ozone chemistry changes. After Kushnir et al., 2019.

Despite common misconceptions, not all annual to decadal predictability stems from the ocean. Indeed, it has been clearly demonstrated that multiyear predictability of the QBO exists in current decadal predictions systems out to lead times of several years (Pohlman et al., 2013; Scaife et al., 2014b). This offers the prospect of a stratospheric contribution to multiyear predictability of the extratropics through the teleconnection with the Arctic Oscillation (Anstey and Shepherd 2014, Gray et al., 2018) and to tropical predictability through links to the MJO (e.g. Martin et al., 2021) and wider tropical climate variability (Haynes et al., 2021).

Although it is more important on multidecadal timescales (see below), external forcing of the stratosphere can also act as a source of decadal predictability. Forced climate signals from changes in greenhouse gases or stratospheric effects such as ozone depletion occur on a much longer timescale 
than the lead time of decadal forecasts but their contribution to the skill of predictions is not trivial. For example, it is not immediately obvious whether the slow changes from multidecadal forced signals would simply be swamped by unpredictable internal variability on decadal timescales, rendering long term external forcing changes useless for decadal predictions. However, this is not the case and longterm forcing is now known to be an important source of decadal prediction skill (Smith et al., 2019, 2020).

External forcing involving the stratosphere on shorter timescales is also important for annual to decadal predictions. The stratosphere has long been known to be influenced by volcanic eruptions, particularly in the case of tropical volcanic eruptions which are powerful enough to inject significant quantities of sulphur dioxide into the atmosphere. Here it reacts with water to form sulphuric acid and persists in aerosol form, leading to predictable multiyear global surface cooling, tropical stratospheric warming and an intensification of the westerly stratospheric polar vortex in the extratropics (Robock and Mao 1992). Although the sample of observed events is limited, modelling studies have reproduced an observed post-eruption intensification of the westerly winds in the stratosphere and some impacts on the surface Arctic Oscillation. However, generations of models have struggled to reproduce the twoyear persistence of volcanic effects seen in observations and the observed magnitude of the effect on the winter AO (e.g. Stenchikov et al., 2006; Marshall et al., 2009; Charlton-Perez et al., 2013, Bittner et al., 2016). In addition to these changes in the atmosphere, the intensification of stratospheric westerlies and hence Arctic Oscillation also combines with surface cooling of the ocean to generate predictable changes in the Atlantic meridional overturning circulation (Reichler et al., 2012) which can extend the volcanic influence to decadal timescales (Swingedouw et al., 2015). Finally, although the mechanism is debated, there is also evidence of a multiyear effect of tropical volcanic eruptions on ENSO, presumably requiring the persistent radiative forcing that arises through the long residence time of volcanic products, particularly sulphate aerosols, in the stratosphere. This reportedly increases the frequency of El Nino events by a factor of two in the years following volcanic eruptions (Adams et al., 2003), again suggesting an important source of multiannual predictability via the stratosphere.

A second source of multiannual predictability from external forcing originates from solar variability and in particular the 11-year solar activity cycle. Although a number of alternative mechanisms have been proposed (see Gray et al., 2010 for a review), the established mechanism for surface effects via the stratosphere is the change in the polar vortex that results from changes in upper stratospheric heating over the course of each cycle between solar minimum and solar maximum. Atmospheric wave-mean flow interactions amplify the initial radiatively driven change and drive its descent to the troposphere (Kodera and Kuroda 2002; Marsh et al 2007; Ineson et al., 2011; Givon et al., 2021), where changes in the extratropical jets result in a negative (positive) Arctic Oscillation pattern following solar minimum (maximum). There is also evidence that it contributes to interannual prediction skill (Dunstone et al., 2016) and an interesting aspect that has emerged in recent years is the integrating effect of the ocean on solar induced changes in the NAO via interannual persistence of ocean heat content anomalies which leads to a lag of around 3 years $(\pi / 2$ cycles) in the peak response, as would be expected if the ocean is integrating the effects of a periodic solar forcing (Scaife et al., 2013; Gray et al., 2013; Andrews et al., 2015; Thiéblemont et al., 2015). However, debate continues as to whether the solar signal is indeed large enough to be detectable in observations in the presence of large internal tropospheric variability (Chiodo et al., 2019).

The currently recognised role of the stratosphere in decadal forecasts of surface climate again appears mainly via the impact on annular modes and, in the northern hemisphere, the North Atlantic Oscillation. Indeed, while much work is still needed to attribute variations in these modes to external forcing or internal variations, current decadal prediction systems are now able to produce skilful predictions of variations in the NAO on multiyear lead times (Smith et al., 2019, 2020; Athanassiadis et al., 2020). These new results are important because they indicate new-found decadal predictability of events like the high NAO of the 1990s which yielded a run of mild but wet and stormy winters in northern Europe 
and the eastern USA. These winters are well known to have caused significant impact for example on the insurance sector (Leckebusch et al., 2007) and coincided with the longest observed absence of SSW events (Pawson and Naujokat 1999; Domeisen 2019). Given indications of coupled stratospheretroposphere variations on decadal timescales (Scaife et al., 2005; Omrani et al., 2014; Garfinkel et al., 2017; Woo et al., 2015), understanding the role of the stratosphere in extratropical decadal predictions needs further investigation.

\section{The stratosphere and multidecadal prediction}

The importance of the stratosphere for climate predictions on multidecadal timescales was generally recognised before its role in predictions on shorter timescales. This is in part a legacy of the early development of stratosphere-troposphere models for ozone depletion studies described in the introduction and partly due to the later development of operational predictions for decadal timescales for example.

Perhaps the best-known case for the stratosphere affecting multidecadal predictions of surface climate is the influence of ozone depletion on the southern annular mode (SAM; Thompson and Solomon 2002, 2005; McLandress et al., 2011; Polvani et al., 2011; Son et al., 2018) where decreasing ozone in the late $20^{\text {th }}$ century lead to a strengthened pole-to-equator temperature gradient, a stronger stratospheric polar vortex and a shift to strong positive SAM phases at the surface. In this case, studies again show the importance of stratospheric resolution to generate the full response, consistent with a genuine downward influence (Karpechko et al., 2008). The associated poleward shift in the tropospheric jet is connected to a delay in the spring breakdown of the stratospheric polar vortex (Byrne et al., 2017) and delivered significant and prolonged changes in rainfall across many regions of the southern hemisphere (Kang et al., 2011; Purich and Son 2012). Implementation of the Montreal Protocol in 1987 and subsequent reductions in the rate of ozone depletion mean that recovery of the ozone layer is now expected over the coming decades and the reversible effects of this on the surface climate form an important element of current multidecadal predictions (Thompson et al., 2011; Previdi and Polvani 2014; Solomon et al., 2016; Banarjee et al., 2020) where they are expected to play an important role alongside other changes in the southern stratosphere due to continuing increases in greenhouse gases (Son et al., 2009; Barnes et al., 2012; Ceppi and Shepherd, 2019).

The more limited effects of ozone depletion in the northern hemisphere meant that the role of the stratosphere in multidecadal predictions took longer to become established. Some early studies found potential amplification of positive Arctic Oscillation trends under climate change when the stratosphere was included (Shindell et al., 2001). However, this was not borne out in later studies as simulations with other fully coupled ocean-troposphere-stratosphere models suggested weakening of the stratospheric polar vortex (e.g. Huebener et al., 2007). Subsequent studies with multiple models also indicated a southward shift in the polar night jet with weakening high latitude winds and strengthening subtropical winds (Scaife et al., 2012; Manzini et al., 2014). These changes result from increased atmospheric wave driving of the winds which can overwhelm the cooling effect of greenhouse gases (Karpechko and Manzini 2012) and can lead to important differences in future surface climate, for example in regional rainfall in areas typically affected by the stratosphere via the Arctic Oscillation and NAO (Scaife et al., 2012). There is still significant uncertainty due to the diversity of modelled stratospheric responses to greenhouse gas increases (Manzini et al., 2014, Simpson et al., 2018, Zappa and Shepherd 2017), and it has proved difficult to identify any clear change in the frequency of sudden stratospheric warmings (Ayarzagüena et al., 2018, 2020; Rao et al., 2020c). This is perhaps due to the competition between strengthening latitudinal temperature gradients near the tropopause and enhanced meridional overturning in the mid stratosphere. There is also strong inherent unpredictable variability from decade to decade in the frequency of SSW occurrence (Butchart et al., 2000; McLandress and Shepherd 2009). 
Other aspects of future climate change where the stratosphere plays a role have also been identified, for example, in the debate over the response to future levels of Arctic sea ice. In this case it seems that the response of the mid-latitude circulation involves a negative shift in the Arctic Oscillation (Screen et al., 2018; Zappa et al., 2018; McKenna et al., 2018). This could again be amplified by interaction with the stratosphere as some studies suggest that the stratospheric response is necessary for a large surface response (Kim et al., 2014), while others highlight that the stratospheric interaction is sensitive to the regional pattern of sea ice decline (McKenna et al., 2018), and still others show evidence of non-linear stratospheric, and stratosphere-mediated surface response (Manzini et al., 2018), coincident with the time when Barents and Kara seas become ice-free (Kretschmer et al., 2020). Furthermore, studies also indicate that the surface climate response to sea ice decline depends systematically on the phase of the stratospheric QBO (Labe et al., 2019).

Although it is much less certain than anthropogenic climate change, there have also been suggestions of a multidecadal decline of external solar irradiance which can impact multidecadal climate predictions via the stratosphere. Previous multidecadal solar minima, so called 'grand minima', have occurred in sunspot records and have been connected to the Little Ice Age period around the end of the $17^{\text {th }}$ century using proxy and other data (Owens et al., 2017). Given recent weak amplitude 11 year solar cycles, there are now suggestions of a future solar 'grand minimum' where the 11 year cycle described above could become muted or even absent for a prolonged period (Lockwood et al., 2010). In this case, the upper stratospheric cooling in the tropics and summer hemisphere can change the meridional temperature gradient in a similar fashion to the 11 year cycle (Maycock et al., 2015) and leads to a negative shift in the AO, the NAO, and hence affects regional climate (Ineson et al., 2015). However, in this case it appears that while regional changes could be significant, they are generally much smaller than the surface warming due to anticipated levels of anthropogenic greenhouse gases (Anet et al., 2013; Ineson et al., 2015; Maycock et al., 2015).

Finally, we note that although frequency variability in teleconnections is observed (e.g. Garfinkel et al., 2019) it is often unclear whether this is a systematic variation or simply due to sampling variability of an underlying stationary process (Jain et al., 2018). There is also growing evidence for systematic climate change in some of the teleconnections by which the stratosphere enables surface predictability. Under future climate change it appears that some of the teleconnections discussed above may strengthen in amplitude. For example, the connection between ENSO and the extratropical Atlantic/European sector increases in future climate projections (Müller and Roeckner 2006; Fereday et al., 2020). Similarly, recent analyses suggest that the MJO teleconnection to the extratropics increases under climate change (Samarasinghe et al., 2020). The same is also true of the extratropical effects of the stratospheric QBO, where in this case, the strength of the teleconnection doubles under future climate change (Rao et al., 2020d) despite the QBO itself becoming weaker (Richter et al., 2020c).

Providing they are not swamped by changes in interannual variability, these strengthening teleconnections suggest a growing importance of the stratosphere in surface climate prediction over the coming decades.

\section{Outlook}

Long range prediction has evolved quickly in recent years (Merryfield et al., 2017; 2020, Butler et al., 2019; Meehl et al., 2021) and this rapid development is due in part to the improved representation of stratospheric processes and stratospheric initial conditions in ensemble prediction systems. The longrange forecast community originally focused on predictability from initial ocean conditions and this remains the primary source of long-range predictability, for example from ENSO, but some of these long-range prediction systems contained poor representations of the stratosphere. In the meantime, those working in parallel on climate modelling of the stratosphere were rarely involved in initialised 
long-range prediction, instead being driven primarily by the ozone depletion problem. Knowledge exchange across fields is important in science and precursors to a new paradigm often occur when a topic is investigated from researchers from outside the field (Kuhn 1970). The crossover and collaboration between long range prediction and stratospheric research communities is no exception and has yielded rapid progress and new insights. Examples where initial atmospheric conditions can provide predictability beyond the usually assumed limit have been demonstrated, particularly for the extratropics but also for the tropics, and we now know that in some situations initial conditions in the ocean have less impact than initial conditions in the stratosphere (Thompson et al 2002; Scaife and Knight 2008; Polvani et al 2017). This suggests that initial atmospheric conditions are likely to be more important for long range forecasts than previously assumed (Mukougawa et al., 2005, 2009; Stockdale et al., 2015; Noguchi et al., 2016, 2020a; Choi and Son 2019; O'Reilly et al., 2019; Nie et al., 2019), not least because the overturning and breaking of Rossby waves in the stratosphere is followed by long lived atmospheric anomalies due to synoptic scale eddy feedbacks that prolong the effects in the troposphere (Kunz and Greatbatch 2013) and enhance long range predictability (Kang et al., 2011).

A notable simplification to understanding the role of the stratosphere, at least in extratropical longrange predictions, is its apparently seamless mechanism across different timescales and different phenomena. Following the early ground-breaking studies showing surface impacts of stratospheric variability and a multitude of studies on individual teleconnections between the stratosphere and surface climate, the projection of stratospheric impacts onto the Arctic Oscillation/North Atlantic Oscillation/Annular Mode circulation patterns across timescales and hemispheres is now well established (see the review by Kidston et al., 2015). This suggests that similar coupling processes occur between the stratosphere and troposphere from months to decades and these processes are responsible for some of the most intense extratropical climate extremes, in winter in the $\mathrm{NH}$ and in late spring/early summer in the southern hemisphere (Karpechko et al., 2018; Fereday et al., 2012, Kautz et al., 2019; Domeisen and Butler 2020).

Some, but not all, leading forecast systems now include a well resolved stratosphere with reasonable representation of relevant processes such as the body force from sub-grid orographic and nonorographic gravity waves. However, many outstanding problems remain. Although their number is increasing, only a subset of current GCMs have the ability to simulate a realistic QBO beyond its decay from initial conditions and it seems that all GCMs have problems with the fidelity of modelled QBO teleconnections, which are either too weak or absent altogether (Scaife et al., 2014a; Kim et al., 2020; Anstey et al., 2021). Even the relatively well studied ENSO teleconnection via the stratosphere to the extratropics still has outstanding questions, such as whether the stratosphere exhibits more SSW events during the La Niña phase (Butler and Polvani 2011; Song and Son 2012). This is not generally reproduced in modelling systems (Garfinkel et al., 2012) but occurred again in the most recent winter at the time of writing in 2021. Similarly, while the increased monthly predictability from the MJO during the easterly phase of the QBO has been detected in monthly forecast experiments, the QBOMJO connection does not persist in longer predictions and simulations with current models (Kim et al., 2020). Research and model development on stratosphere-troposphere interaction, including tropical effects (Noguchi et al., 2020b), will no doubt lead to further progress in resolving this issue (Haynes et al., 2021).

In addition to teleconnection errors, mean biases in stratospheric climate are inevitably present to varying degrees. The common protocol of running a set of retrospective predictions to allow these mean biases to be estimated and hence subtracted from real time predictions may well correct for much of this error. However, the degree to which biases have a nonlinear, state dependent impact on the predictions is not fully understood. In some contexts, the nonlinear impacts of biases may be minimal (Karpechko et al., 2021) while others show sensitivity (Sigmond et al., 2008, 2010) and increases of prediction skill occur under certain background conditions, for example during Easterly QBO phases (Taguchi 2018). Other processes generally omitted from long range predictions include interactive 
variations of ozone and other trace gases. Although reports of impacts and benefits have varied, it is thought that surface signals on interannual timescales come mainly from dynamical rather than chemical changes (Seviour et al 2014; Harari et al., 2019). Nevertheless, some studies suggest detectable effects from interannual variability of ozone and it may be that ozone fluctuations could help to amplify surface signals (Karpechko et al., 2014; Son et al., 2013; Smith and Polvani 2014; Oehrlein et al., 2020; Hendon et al., 2020), providing a further area for future development. Given that the cost of full atmospheric chemistry schemes remains computationally expensive, it seems likely that simple parametrizations of ozone chemistry (e.g. Monge-Sanz et al., 2021) would be valuable in this context.

We end with a pointer to an issue that has now been found to affect all long-range predictions from monthly to seasonal to decadal and multidecadal timescales. So called 'perfect model studies', which test the ability of models to predict their own ensemble members, are now known to underestimate the true predictability of climate in some regions, particularly around the Atlantic basin and so models are better at predicting real world variations than they are at predicting themselves - the so called 'Signal to Noise Paradox' (Scaife and Smith 2018). This is surprising, because perfect model prediction scores are often assumed to represent an upper (rather than lower) limit for prediction of the real world. Whether the stratosphere is involved in the cause of this problem remains to be seen, as it appears first in the troposphere (Domeisen et al., 2020a) and studies are undecided whether predictions of the stratosphere exhibit the same issue (Saito et al., 2017; Stockdale et al., 2015). Nevertheless, the same signal to noise issues may well be the reason for the weaker than observed amplitude of many modelled tropospheric teleconnections involving the stratosphere. Resolving this problem will therefore likely amplify these signals, provide greater levels of prediction skill, and further strengthen the role of the stratosphere in long range predictions of surface climate.

\section{Author Contributions}

AAS wrote the draft manuscript. All other co-authors contributed relevant references and input to revisions and editing of the manuscript. SWS provided Figure 1a.

\section{Acknowledgements}

AAS and SCH were supported by the Met Office Hadley Centre Climate Programme funded by BEIS and Defra. MPB was supported by the Natural Environment Research Council (grant number NE/M006123/1). JHR was supported by the Regional and Global Model Analysis (RGMA) component of the Earth and Environmental System Modeling Program of the U.S. Department of Energy's Office of Biological \& Environmental Research (BER) via NSF Interagency Agreement 1844590. SN was supported by the Japan Society for the Promotion of Science (KAKENHI, Grant Number: 19K14798). EPL was supported by the Australian government's National Environmental Science Program Phase 2. SWS was supported by the National Research Foundation of Korea (NRF) grant funded by the South Korean government (Ministry of Science and ICT) (2017R1E1A1A01074889). DWJT is supported by the US National Science Foundation Climate and Large-Scale Dynamics program. Support from the Swiss National Science Foundation through project PP00P2_170523 to D.D. is gratefully acknowledged. CIG was supported by an European Research Council starting Grant under the European Unions Horizon 2020 research and innovation program (Grant agreement 677756).

\section{References}

Abhik, S. and Hendon, H.H.: Influence of the QBO on the MJO during coupled model multiweek forecasts. Geophysical Research Letters, 46(15), 9213-9221, 2019.

Adams, B. J., Mann, M. and Ammann, C. Proxy evidence for an El Niño-like response to volcanic forcing. Nature, 426, 274-278, 2003. 

the solar cycle over the period 1960-2009. Env. Res. Lett. 10, L054022, 2015.

Anet, J. G., et al.: Impact of a potential 21 st century "grand solar minimum" on surface temperatures and stratospheric ozone, Geophys. Res. Lett., 40, 4420- 4425, doi:10.1002/grl.50806, 2003.

Anstey, J.A. and Shepherd, T.G.: High-latitude influence of the Quasi-Biennial Oscillation. Quart. J. Roy. Meteor. Soc., 140, 1-21, 2014.

Anstey, J.A., Simpson, I.R., Richter, J.H., Naoe, H., Taguchi, M., Serva, F., et al.: Teleconnections of the Quasi-Biennial Oscillation in a multi-model ensemble of QBO-resolving models. Q J R Meteorol Soc, 1-26, 2021.

Ayarzagüena, B., L.M. Polvani, U. Langematz, and CCMI co-authors: No robust evidence of future changes in major stratospheric sudden warmings: A multi-model assessment from CCMI, Atmos. Chem. Phys., 18, 11277-11287, 2018.

Ayarzagüena, B., Barriopedro, D., Garrido-Perez, J. M., Abalos, M., de la Cámara, A., GarcíaHerrera, R., et al.: Stratospheric connection to the abrupt end of the 2016/2017 Iberian drought. Geophysical Research Letters, 45, 12, 639- 12, 646, 2018.

Ayarzagüena et al.: Uncertainty in the response of stratospheric sudden warmings and stratospheretroposphere coupling to quadrupled CO2 concentrations in CMIP6 models, J. Geophys. Res., 126, 6, e2019JD032345, 2020.

Baehr, J., Fröhlich, K., Botzet, M., Domeisen, D. I. V., Kornblueh, L., Notz, D., et al.: The prediction of surface temperature in the new seasonal prediction system based on the MPI-ESM coupled climate model. Climate Dynamics, 44(9-10), 2723-2735, 2015.

Baldwin, M. P., and Dunkerton, T. J.: Propagation of the Arctic Oscillation from the stratosphere to the troposphere, J. Geophys. Res., 104 (D24), 30937-30946, 1999.

Baldwin, M.P. and T.J. Dunkerton: Stratospheric Harbingers of Anomalous Weather Regimes. Science, 294, 5542, 581-584, 2001.

Baldwin M.P., David B. Stephenson, David W. J. Thompson, Timothy J. Dunkerton, Andrew J. Charlton, Alan O'Neill. Stratospheric Memory and Skill of Extended-Range Weather Forecasts. Science, 301, 636-640, 2003.

Baldwin M.P., et al.: 100 Years of Progress in Understanding the Stratosphere and Mesosphere. Met. Monographs, 59, 27.1-27.62, 2019.

Baldwin, M. P., Ayarzagüena, B., Birner, T., Butchart, N., Butler, A. H., Charlton-Perez, A. J., et al.: Sudden stratospheric warmings. Reviews of Geophysics, 59, e2020RG000708, 2021.

Balmaseda, M.A., Ferranti, L., Molteni, F. and Palmer, T.N.: Impact of 2007 and 2008 Arctic ice anomalies on the atmospheric circulation: Implications for long-range predictions. Q.J.R. Meteorol. Soc., 136: 1655-1664, 2010.

Barnes, E.A, N.W. Barnes and L.M. Polvani: Delayed Southern Hemisphere climate change induced by stratospheric ozone recovery, as projected by the CMIP5 models, J. Climate, 27, 852-867, 2014.

Barnes, E. A., Samarasinghe, S. M., Ebert-Uphoff, I., \& Furtado, J. C.: Tropospheric and stratospheric causal pathways between the MJO and NAO. Journal of Geophysical Research: Atmospheres, 124, 9356-9371, 2019. 

Ocean 35, 293-331, 1997.

Bittner, M., Timmreck, C., Schmidt, H., Toohey, M., and Krüger, K.: The impact of wave-mean flow interaction on the Northern Hemisphere polar vortex after tropical volcanic eruptions, J. Geophys. Res. Atmos., 121, 5281- 5297, 2016.

Blackport, R. and J.A. Screen. Weakened evidence for mid-latitude impacts of Arctic warming. Nature. Clim. Change, 10, 1065-1666, 2020.

Boer, G.J., Hamilton, K. QBO influence on extratropical predictive skill. Clim Dyn 31, 987-1000, 2008.

Boville, B. A.: The Influence of the Polar Night Jet on the Tropospheric Circulation in a GCM, J. Atm. Sci., 41(7), 1132-1142, 1984.

Butchart, N., Austin, J., Knight, J. R., Scaife, A. A., \& Gallani, M. L.: The Response of the Stratospheric Climate to Projected Changes in the Concentrations of Well-Mixed Greenhouse Gases from 1992 to 2051, Journal of Climate, 13(13), 2142-2159, 2000.

Butler, A.H., A. Charlton-Perez, D.I.V. Domeisen, I.R. Simpson, and J. Sjoberg, The predictability of Northern Hemisphere final stratospheric warmings and their surface impacts, Geophys. Res. Lett., 46, 10578-10588, 2019.

Butler A.H., Arribas A., Athanassiadou M., Baehr J., Calvo N., Charlton-Perez A., Deque M., Domeisen D.I.V., Fröhlich K., Hendon H., Imada Y., Ishii M., Iza M., Karpechko A.Y., Kumar A., Maclachlan C., Merryfield W.J., Muller W.A., O’Neill A., Scaife A.A., Scinocca, J., Sigmond M., Stockdale T.N., Yasuda T.: The Climate-system Historical Forecast Project: Do stratosphereresolving models make better seasonal climate predictions in boreal winter? Quart. J. Roy. Met. Soc., 142, 1413-1427, doi:10.1002/qj.2743, 2016.

Butler, A.H., Z.D. Lawrence, S.H. Lee, S.P. Lillo, and C.S. Long: Differences between the 2018 and 2019 stratospheric polar vortex split events, Quar. Jour. Roy. Met. Soc., 1-19, 2020.

Butler, A.H., A. Charlton-Perez, D.I.V. Domeisen, C. Garfinkel, E.P. Gerber, P. Hitchcock, A.-Yu Karpechko, A.C. Maycock, M. Sigmond, I. Simpson, S.-W. Son. Sub-seasonal Predictability and the Stratosphere- Chapter 11, The Gap Between Weather and Climate Forecasting, p. 223-241, 2019.

Butler, A.H., L.M. Polvani and C. Deser: Separating the stratospheric and tropospheric pathways of El Niño-Southern Oscillation teleconnections, Environ. Res. Lett., 9, 024014, 2014.

Butler A.H. and L.M. Polvani: El Niño, La Niña, and stratospheric sudden warmings: A re-evaluation in light of the observational record, Geophys. Res. Lett., 38, L13807, 2011.

Byrne, N.J., Shepherd, T.G., Woollings, T. and Plumb, R.A.: Non-stationarity in Southern Hemisphere climate variability associated with the seasonal breakdown of the stratospheric polar vortex. J. Clim., 30, 7125-7139, 2017.

Byrne, N. J., and T. G. Shepherd: Seasonal persistence of circulation anomalies in the Southern Hemisphere stratosphere and its implications for the troposphere. J. Clim., 31, 3467-3483, doi:10.1175/JCLI-D-17-0557.1, 2018.

Byrne, N.J., Shepherd, T.G. and Polichtchouk, I.: Subseasonal-to-seasonal predictability of the Southern Hemisphere eddy-driven jet during austral spring and early summer. J. Geophys. Res., 124, 6841-6855, 2019. 
Cai, M., Y. Yu, Y. Deng, H.M. van den Dool, R. Ren, S. Saha, X. Wu, J. Huang: Feeling the pulse of the stratosphere: an emerging opportunity for predicting continental-scale cold-air outbreaks 1 month in advance. Bull. Am. Meteorol. Soc., 97, pp. 1475-1489, 2016.

Cassou, C.: Intraseasonal interaction between the Madden-Julian Oscillation and the North Atlantic Oscillation. Nature 455, 523-527, 2008.

Christiansen B.: Downward propagation and statistical forecast of the near-surface weather. J. Geophys. Res. Atmos., 110, 2005.

Ceppi, P. and Shepherd, T.G.: The role of the stratospheric polar vortex for the austral jet response to greenhouse gas forcing. Geophys. Res. Lett., 46, 6972-6979, 2019.

Charlton, A.J., O'Neill, A., Stephenson, D.B., Lahoz, W.A. and Baldwin, M.P.: Can knowledge of the state of the stratosphere be used to improve statistical forecasts of the troposphere?. Q.J.R. Meteorol. Soc., 129: 3205-3224, 2003.

Charlton-Perez AJ, et al:: On the lack of stratospheric dynamical variability in low-top versions of the CMIP5 models, J. Geophys. Res. Atmos, 118, 2494-2505, 2013.

Charlton-Perez, A. J., Ferranti, L. and Lee, R. W.: The influence of the stratospheric state on North Atlantic weather regimes. Quarterly Journal of the Royal Meteorological Society, 144 (713). pp. 1140-1151. ISSN 1477-870X, 2018.

Chiodo, G., Oehrlein, J., Polvani, L.M. et al.: Insignificant influence of the 11-year solar cycle on the North Atlantic Oscillation. Nat. Geosci. 12, 94-99, 2019.

Choi, J., and S.-W. Son: Stratospheric initial condition for skillful surface prediction in the ECMWF model, Geophysical Research Letters, 21, 12556-12564, 2019.

Cohen J. and D. Entekhabi: Eurasian snow cover variability and northern hemisphere climate variability. Geophys. Res. Lett., 26, 345-348, 1999.

Cohen, J., and Jones, J.: A new index for more accurate winter predictions. Geophysical Research Letters, 38, L21701, 2011.

Cohen J., Furtado JC, Jones J, Barlow M, Whittleston D, Entekhabi D.: Linking Siberian snow cover to precursors of stratospheric variability. J Clim., 27(14), 5422-5432, 2014.

Crutzen P.J.: Estimates of Possible Variations in Total Ozone Due to Natural Causes and Human Activities. Ambio, 3, No. 6, 201-210, 1974.

Dai, A., Song, M.: Little influence of Arctic amplification on mid-latitude climate. Nat. Clim. Chang. 10, 231-237, 2020.

Davies, P.A., McCarthy, M., Christidis, N., Dunstone, N., Fereday, D., Kendon, M., Knight, J.R., Scaife, A.A. and Sexton, D.: The wet and stormy UK winter of 2019/2020. Weather, https://doi.org/10.1002/wea.3955, 2021.

Domeisen, D. I. V., Sun, L., \& Chen, G.: The role of synoptic eddies in the tropospheric response to stratospheric variability. Geophysical Research Letters, 40, 1-5, 2013.

Domeisen, D. I. V., Badin, G., \& Koszalka, I. M.: How Predictable Are the Arctic and North Atlantic Oscillations? Exploring the Variability and Predictability of the Northern Hemisphere. Journal of Climate, 31(3), 997-1014, 2018.

Domeisen, D. I. V.: Estimating the Frequency of Sudden Stratospheric Warming Events From Surface Observations of the North Atlantic Oscillation. Journal of Geophysical Research-Atmospheres, 124(6), 3180-3194, 2019. 
Domeisen, D. I. V., Garfinkel, C. I., \& Butler, A. H.: The Teleconnection of El Niño Southern Oscillation to the Stratosphere. Reviews of Geophysics, 57(1), 5-47, 2019.

704 Domeisen, D. I. V., \& Butler, A. H.: Stratospheric drivers of extreme events at the Earth's surface.

705 Communications Earth \& Environment, 1-8, 2020.

706 Domeisen, D.I.V., A.H. Butler, A.J. Charlton-Perez, B. Ayarzaguena, M.P. Baldwin, E. Dunn-

707 Sigouin, J.C. Furtado, C.I. Garfinkel, P. Hitchcock, A. Yu. Karpechko, H. Kim, J. Knight, A.L. Lang,

708 E.-P. Lim, A. Marshall, G. Roff, C. Schwartz, I.R. Simpson, S.-W. Son, M. Taguchi: The role of

709 stratosphere-troposphere coupling in sub-seasonal to seasonal prediction. 1. Predictability in the

710 Stratosphere, J. Geophys. Res., 125, e2019JD030920, 2020a.

Domeisen, D.I.V., A.H. Butler, A.J. Charlton-Perez, B. Ayarzaguena, M.P. Baldwin, E. DunnSigouin, J.C. Furtado, C.I. Garfinkel, P. Hitchcock, A. Yu. Karpechko, H. Kim, J. Knight, A.L. Lang, E.-P. Lim, A. Marshall, G. Roff, C. Schwartz, I.R. Simpson, S.-W. Son, M. Taguchi: The role of stratosphere-troposphere coupling in sub-seasonal to seasonal prediction. 2. Predictability arising from stratosphere-troposphere coupling, J. Geophys. Res., 125, e2019JD030923, $2020 \mathrm{~b}$.

Douville H.: Stratospheric polar vortex influence on Northern Hemisphere winter climate variability. Geophys. Res. Lett., 36 (2009), L18703, 2009. $\mathrm{ClOx} / \mathrm{NOx}$ interaction. Nature 315, 207-210, 1985.

Fels S.B.: Radiative-Dynamical Interactions in the Middle Atmosphere. Advances in Geophysics, 28, Part A, 277-300, 1985.

Fereday D. R. et al.: Seasonal forecasts of northern hemisphere winter 2009/10. Environ. Res. Lett. 7 , 034031, 2012.

724

Fereday D. et al.: Tropical rainfall drives stronger future ENSO-NAO teleconnection in CMIP5 models. Geophys. Res. Lett., 47, e2020GL088664, 2020.

Fletcher, C. G., S. C. Hardiman, P. J. Kushner, and J. Cohen: The dynamical response to snow cover perturbations in a large ensemble of atmospheric GCM integrations, J. Climate, 22(5), 1208-1222, doi:10.1175/2008JCLI2505.1, 2009.

Furtado, J.C., Cohen, J.L., Butler, A.H. et al.: Eurasian snow cover variability and links to winter climate in the CMIP5 models. Clim Dyn 45, 2591-2605, 2015.

Garfinkel, C.I., C. Schwartz, D.I.V. Domeisen, S.-W. Son, A.H. Butler, and I.P. White, Extratropical atmospheric predictability from the Quasi-Biennial Oscillation in subseasonal forecast models, Jour. Geophys. Res., 123 (15), 7855-7866, 2018.

Garfinkel, C. I., Schwartz, C., Butler, A. H., Domeisen, D. I. V., Son, S.-W., \& White, I. P.: Weakening of the Teleconnection From El Niño-Southern Oscillation to the Arctic Stratosphere Over the Past Few Decades: What Can Be Learned From Subseasonal Forecast Models? Journal of Geophysical Research-Atmospheres, 124(14), 7683-7696, 2019.

Garfinkel, C.I. and C. Schwartz: MJO-related tropical convection anomalies lead to more accurate stratospheric vortex variability in subseasonal forecast models, GRL, doi:10.1002/2017GL074470, 2017.

Garfinkel, C. I., Son, S.-W., Song, K., Aquila, V., and Oman, L. D.: Stratospheric variability contributed to and sustained the recent hiatus in Eurasian winter warming, Geophys. Res. Lett., 44, 374-382, 2017. 
Garfinkel C.I., C. Schwartz, D. I. P. Domeisen, S-W Son, A. H. Butler, I. P. White: Extratropical atmospheric predictability from the Quasi-Biennial Oscillation in subseasonal forecast models, JGR, doi: 10.1029/2018JD028724.., 123 (15), 7855-7866, 2018.

Garfinkel, C. I., A.H. Butler, D. W. Waugh, M. M. Hurwitz, L. M. Polvani: Why might stratospheric sudden warmings occur with similar frequency in El Nino and La Nina winters?, J. Geophys. Res. Atmos., 117, D19106, doi:10.1029/2012JD017777, 2012.

Garfinkel, C. I., Feldstein, S. B., Waugh, D. W., Yoo, C., and Lee, S.: Observed connection between stratospheric sudden warmings and the Madden-Julian Oscillation, Geophys. Res. Lett., 39, L18807, 2012.

Gerber, E. P., A. Butler, N. Calvo, A. Charlton-Perez, M. Giorgetta, E. Manzini, J. Perlwitz, L. M. Polvani, F. Sassi, A. A. Scaife, T. A. Shaw, S.-W. Son and S. Watanabe: Assessing and Understanding the Impact of Stratospheric Dynamics and Variability on the Earth System. Bull. Amer. Met. Soc., 93, 845-859, 2012.

Givon, Y., Garfinkel, C.I. and White, I.: Transient extratropical response to solar ultraviolet radiation in the Northern Hemisphere winter. Journal of Climate, 34(9), pp.3367-3383, 2021.

Graversen, R. G., and B. Christiansen: Downward propagation from the stratosphere to the troposphere: A comparison of the two hemispheres. J. Geophys. Res. Atmos., 108, 4780, 2003.

Gray, L. J., et al.: Solar influences on climate, Rev. Geophys., 48, RG4001, 2010.

Gray, L. J., Scaife, A. A., Mitchell, D. M., Osprey, S., Ineson, S., Hardiman, S., Butchart, N., Knight, J., Sutton, R., and Kodera, K.: A lagged response to the 11 year solar cycle in observed winter Atlantic/European weather patterns, J. Geophys. Res. Atmos., 118, 13,405- 13, 420, 2013.

Gray, L. J., Anstey, J. A., Kawatani, Y., Lu, H., Osprey, S., and Schenzinger, V.: Surface impacts of the Quasi-Biennial Oscillation, Atmos. Chem. Phys., 18, 8227-8247, 2018.

Hall, R. J., Scaife, A. A., Hanna, E., Jones, J. M., \& Erdélyi, R.: Simple statistical probabilistic forecasts of the winter NAO. Weather and Forecasting, 32(4), 1585-1601, 2017.

Harari, O., C.I. Garfinkel, O. Morgenstern, G. Zeng, S. Tilmes, D. Kinnison, M. Deushi, P. Jockel, A. Pozzer, and F. M. O'Connor, Influence of Arctic Stratospheric Ozone on Surface Climate in CCMI models, ACP, doi: 10.5194/acp-2018-1031, 2019.

Hardiman, Steven C., Adam A. Scaife, Nick. J. Dunstone, and Lin Wang: Subseasonal vacillations in the winter stratosphere, Geophys. Res. Lett., 47, e2020GL087766, 2020a.

Hardiman, Steven C., Nick J. Dunstone, Adam A. Scaife, Doug M. Smith, Jeff R. Knight, Paul Davies, Martin Claus, and Richard J. Greatbatch (2020b), Predictability of European winter 2019/20: Indian Ocean dipole impacts on the NAO, Atmos. Sci. Lett. 2020, e1005, $2020 \mathrm{~b}$.

Hardiman, Steven C., Neal Butchart, Andrew J. Charlton-Perez, Tiffany A. Shaw, Hideharu Akiyoshi, Andreas Baumgaertner, Slimane Bekki, Peter Braesicke, Martyn Chipperfield, Martin Dameris, Rolando R. Garcia, Martine Michou, Steven Pawson, Eugene Rozanov, and Kiyotaka Shibata: Improved predictability of the troposphere using stratospheric final warmings, J. Geophys. Res., 116, D18113, 11 PP., 2011.

Harnik N.. Observed stratospheric downward reflection and its relation to upward pulses of wave activity. J. Geophys. Res., 114, Article D08120, 2009.

Harnik, N. and R.S. Lindzen. The effect of reflecting surfaces on the vertical structure and variability of stratospheric planetary waves. J. Atmos. Sci., 58, 2872-2894, 2001. 

Control" of Extratropical Diabatic Circulations by Eddy-Induced Mean Zonal Forces, Journal of Atmospheric Sciences, 48(4), 651-678, 1991. I.: The influence of the stratosphere on the tropical troposphere. J. Meteor. Soc. Japan, (accepted subject to final small changes), 2021. hemisphere. Nat Clim Change 8(11), 954-963, 2018

Hendon, H. H., and S. Abhik: Differences in vertical structure of the Madden-Julian oscillation associated with the quasi-biennial oscillation. Geophys. Res. Lett., 45, 4419-4428, 2018.

Hendon, H. H., E. -P. Lim, and S. Abhik: Impact of Interannual Ozone Variations on the Downward Coupling of the 2002 Southern Hemisphere Stratospheric Warming. J. Geophys. Res. Atmos., 1-16, doi:10.1029/2020JD032952, 2020.

Hitchcock, P., Shepherd, T.G., Taguchi, M., Yoden, S. and Noguchi, S.: Lower-stratospheric radiative damping and Polar-night Jet Oscillation events. J. Atmos. Sci., 70, 1391-1408, 2013.

Hitchcock, P., \& Simpson, I. R.: The Downward Influence of Stratospheric Sudden Warmings,

804 Journal of the Atmospheric Sciences, 71(10), 3856-3876, 2014.

Hitchcock, P., Haynes, P.H.: Stratospheric control of planetary waves. Geophys. Res. Lett., 43, 11,884-11,892, doi:10.1002/2016GL071372, 2016.

Holton, J.R., H.-C. Tan. The influence of the equatorial quasi-biennial oscillation on the global circulation at $50 \mathrm{mb}$. J. Atmos. Sci., 37, 2200-2208, 1980.

Honda, M., Inoue, J., and Yamane, S.: Influence of low Arctic sea-ice minima on anomalously cold Eurasian winters, Geophys. Res. Lett., 36, L08707, doi:10.1029/2008GL037079, 2009. climate simulations using a fully coupled ocean-troposphere-stratosphere general circulation modelPhil. Trans. R. Soc. A.3652089-2101, 2007.

Hurwitz, M. M., Newman, P. A., and Garfinkel, C. I.: On the influence of North Pacific sea surface temperature on the Arctic winter climate, J. Geophys. Res., 117, D19110, 2012. Ineson S. and Scaife A.A.: The role of the stratosphere in the European climate response to El Nino.

817 Nature Geoscience, 2, 32-36, 2009.

818 Ineson S., A. A. Scaife, J.R. Knight, J.C. Manners, N.J. Dunstone, L.J. Gray and J.D. Haigh: Solar 819 Forcing of Winter Climate Variability in the Northern Hemisphere. Nat. Geosci., 4, 753-757, 2011.

820 Ineson, S., Maycock, A., Gray, L. et al.: Regional climate impacts of a possible future grand solar 821 minimum. Nat Commun 6, 7535, 2015. and tropospheric circulation in northern autumn. J. Geophys. Res. Atmos., 116, 2011.

824 Jain, S., Scaife, A.A. \& Mitra, A.K.: Skill of Indian summer monsoon rainfall prediction in multiple 

planetary wave propagation changes. Tellus A Dyn Meteorol Oceanogr 65(1):19375, 2013. Driven by the Stratosphere, Journal of Climate, 30(12), 4463-4475, 2017. S., Decremer, D., Weisheimer, A., Balsamo, G., Keeley, S. P. E., Mogensen, K., Zuo, H., and MongeSanz, B. M.: SEAS5: the new ECMWF seasonal forecast system, Geosci. Model Dev., 12, 1087-

$8341117,2019$.

835 Joshi, M. M., A. J. Charlton, and A. A. Scaife: On the influence of stratospheric water vapor changes on the tropospheric circulation. Geophys. Res. Lett., 33, L09806, 2006. warming events. Geophysical Research Letters, 45, 13,124-13,132, 2018. in present and future climate? Geophysical Research Letters, 48, e2021GL093215, 2021.

Kang, I.S., Kug, JS., Lim, MJ. et al: Impact of transient eddies on extratropical seasonal-mean predictability in DEMETER models. Clim Dyn 37, 509-519, 2011.

843 Kang, S.M., L.M. Polvani, J.C. Fyfe and M. Sigmond: Impact of Polar Ozone Depletion on 844 Subtropical Precipitation, Science, 332, 951-954, 2011. changes in the Southern Hemisphere troposphere in coupled climate models. Geophys. Res. Lett., 847 L20806, 2008.

848 Karpechko, A. Y., and Manzini, E.: Stratospheric influence on tropospheric climate change in the 849 Northern Hemisphere, J. Geophys. Res., 117, D05133, doi:10.1029/2011JD017036, 2012.

Karpechko, A. Yu., J. Perlwitz, and E. Manzini: A model study of tropospheric impacts of the Arctic ozone depletion 2011, J. Geophys. Res. Atmos., 119, 7999-8014, 2014 propagation of sudden stratospheric warmings, Quart. J. Roy. Meteor. Soc., v. 143, 704, 1459-1470, 8542017.

Karpechko A. Y., A. Charlton-Perez, M. Balmaseda, N. Tyrrell, and F. Vitart: Predicting sudden stratospheric warming 2018 and its climate impacts with a multimodel ensemble, Geophys. Res. Lett., $85745,13538-13546,2018$.

858 Karpechko A. Yu.: Predictability of Sudden Stratospheric Warmings in the ECMWF Extended-Range 859 Forecast System, Mon. Wea. Rev., 146(4), 1063-1075, doi: 10.1175/MWR-D-17-0317.1, 2018.

860 Karpechko, AY, Tyrrell, NL, Rast, S.: Sensitivity of QBO teleconnection to model circulation biases. 861 Q J R Meteorol Soc. 147, 2147-2159, 2021. 

loss. Nat Comm., 5, 4646, 2014.

870 Kim, H., Caron, J. M., Richter, J. H., \& Simpson, I. R.: The lack of QBO-MJO connection in CMIP6 871 models. Geophysical Research Letters, 47, e2020GL087295, 2020.

King, M.P., Hell, M. \& Keenlyside, N. Investigation of the atmospheric mechanisms related to the autumn sea ice and winter circulation link in the Northern Hemisphere. Clim. Dyn., 46, 1185-1195, 8742016

875 King, A. D., A.H. Butler, M. Jucker, N.O. Earl, and I. Rudeva, Observed relationships between 876 sudden stratospheric warmings and European climate extremes, J. Geophys. Res., 124, 13943-13961, 8772019.

Kodera, K. and Kuroda, Y. Dynamical response to the solar cycle. J. Geophys. Res. 107, 4749, 2002. Kolstad, E. W., \& Screen, J. A.. Non-stationary relationship between autumn Arctic sea ice and the winter North Atlantic Oscillation. Geophysical Research Letters, 46, 7583- 7591, 2019.

Knight J. et al.: Predictability of European winters 2017/2018 and 2018/2019: Contrasting Influences from the Tropics and Stratosphere. Atm. Sci. Lett., e1009, doi.org/10.1002/asl.1009, 2020. mean zonal wind perturbation to the troposphere. Geophys. Res. Lett., 17, 9, 0094-8276, 1990.

Kodera, K.: On the origin and nature of the interannual variability of the winter stratospheric circulation in the northern hemisphere, J. Geophys. Res., 100 (D7), 14077- 14087, 1995.

Kodera, K., Mukougawa, H., and Itoh, S.: Tropospheric impact of reflected planetary waves from the stratosphere, Geophys. Res. Lett., 35, L16806, doi:10.1029/2008GL034575, 2008.

Kretschmer, M., Coumou, D., Donges, J.F., and Runge, J.: Using causal effect networks to analyze different Arctic drivers of midlatitude winter circulation. J. Clim., 29, 4069-4081, 2016.

Kretschmer, M., Zappa, G. and Shepherd, T.G.: The role of Barents-Kara sea ice loss in projected polar vortex changes. Wea. Clim. Dyn., 1, 715-730, 2020. Stratospheric Variability, Journal of the Atmospheric Sciences, 70(7), 2103-2118, 2013. study of winter 2003-2004. Geophysical Research Letters, 35, L19701, 2008.

Kushnir, Y., Scaife, A.A., Arritt, R. et al.: Towards operational predictions of the near-term climate. Nature Clim. Change 9, 94-101, 2019.

Kushner P.J. and L.M. Polvani: Stratosphere-troposphere coupling in a relatively simple AGCM: The 901 role of eddies, J. Climate, 17, 629-639, 2004. 

Arctic Oscillation and ozone loss. Journal of Geophysical Research: Atmospheres, 125, 909 e2020JD033271, 2020.

910 Leckebusch, G. C., Ulbrich, U., Fröhlich, L., and Pinto, J. G.: Property loss potentials for European midlatitude storms in a changing climate, Geophys. Res. Lett., 34, L05703, 2007. Greenland pattern and its relationship with the polar vortex in S2S forecast models. QJ R Meteorol

914 Soc. 146: 4083-4098, 2020a.

915 Lee, S.H., Z.D. Lawrence, A.H. Butler, and A. Karpechko. Seasonal forecasts of the exceptional 916 Northern Hemisphere winter of 2020, Geophys. Res. Lett., 47, e2020GL090328, 2020 b.

917 Leung, T.Y., Leutbecher, M., Reich, and Shepherd, T.G.. Impact of the mesoscale range on error 918 growth and the limits to atmospheric predictability. J. Atmos. Sci., 77, 3769-3779, 2020.

919 L'Heureux, M.L., Levine, A.F.Z., Newman, M., Ganter, C., Luo, J.-J., Tippett, M.K. and Stockdale, 920 T.N.: ENSO Prediction. In El Niño Southern Oscillation in a Changing Climate (eds M.J. McPhaden, 921 A. Santoso and W. Cai), 2020.

Lim, E.-P., H. H. Hendon, and D. W. J. Thompson: Seasonal evolution of stratosphere-troposphere coupling in the Southern Hemisphere and implications for the predictability of surface climate. J. Geophys. Res. Atmos., 123, 12,002-12,016, 2018.

925

Lim, E.-P., H. H. Hendon, G. Boschat, D. Hudson, D. W. J. Thompson, A. J. Dowdy, and J. Arblaster: Australian hot and dry extremes induced by weakening of the stratospheric polar vortex. Nature Geoscience, 12 (11), 896-901, 2019.

Lim, E.-P., and Coauthors: The 2019 Southern Hemisphere polar stratospheric warming and its impacts. BAMS. 102 (6), E1150-E1171, 2021.

Lim, Y., S.-W. Son, A. G. Marshall, H. H. Hendon, and K.-H. Seo: Influence of the QBO on MJO prediction skill in the subseasonal-to-seasonal prediction models, Climate Dynamics, 53, 1681-1695, 2019.

Lin, H., Brunet, G., \& Derome, J.: An Observed Connection between the North Atlantic Oscillation and the Madden-Julian Oscillation, Journal of Climate, 22(2), 364-380, 2009.

Lockwood, M.: Solar change and climate: An update in the light of the current exceptional solar minimum, Proc. R. Soc. A, 466, 303-329, 2010.

Lorenz, E.N.: The predictability of a flow which possesses many scales of motion. Tellus, 21: 289307, 1969.

Manzini, E., Giorgetta, M. A., Esch, M., Kornblueh, L., \& Roeckner, E.: The Influence of Sea Surface Temperatures on the Northern Winter Stratosphere: Ensemble Simulations with the MAECHAM5 Model, Journal of Climate, 19(16), 3863-3881, 2006.

Manzini, E., Karpechko, A. Y., and Kornblueh, L.: Nonlinear Response of the Stratosphere and the North Atlantic-European Climate to Global Warming, Geophys. Res. Lett., 45, 4255-4263, 2018.

Mariotti, A., C. Baggett, E. A. Barnes, E. Becker, A.H. Butler, D.C. Collins, P.A. Dirmeyer, L. Ferranti, N.C. Johnson, J. Jones, B. P. Kirtman, A.L. Lang, A. Molod, M. Newman, A.W. Robertson, S. Schubert, Waliser, D.E. and J. Albers, Windows of opportunity for skillful forecasts subseasonal to seasonal and beyond, BAMS, 101, E608-E625, 2020. 
949 K.: Modeling the whole atmosphere response to solar cycle changes in radiative and geomagnetic

950 forcing, J. Geophys. Res., 112, D23306, 2007.

Marshall A. and A.A. Scaife: Improved predictability of stratospheric sudden warming events in an AGCM with enhanced stratospheric resolution. J. Geophys. Res., 115, D16114, 2010.

Marshall, A.G., Hendon, H.H., Son, S.W. and Lim, Y.: Impact of the quasi-biennial oscillation on predictability of the Madden-Julian oscillation. Climate Dynamics, 49(4), pp.1365-1377, 2017.

Martin, Z., Wang, S., Nie, J., \& Sobel, A.: The Impact of the QBO on MJO Convection in CloudResolving Simulations, Journal of the Atmospheric Sciences, 76(3), 669-688, 2019. Cold Spells, Monthly Weather Review, 148(4), 1675-1690, 2020. Hardiman, S. C., Mitchell, D. M., and Osprey, S. M.: Possible impacts of a future grand solar minimum on climate: Stratospheric and global circulation changes, J. Geophys. Res. Atmos., 120, 964 9043-9058, 2015.

McKenna, C.M., Bracegirdle, T.J., Shuckburgh, E.F., Haynes, P.H., Joshi, M.M.: Arctic sea-ice loss 966 in different regions leads to contrasting Northern Hemisphere impacts. Geophys. Res. Lett., 45, 945$967954,2018$.

968 MacLachlan, C., Arribas, A., Peterson, K.A., Maidens, A., Fereday, D., Scaife, A.A., Gordon, M., 969 Vellinga, M., Williams, A., Comer, R.E., Camp, J., Xavier, P. and Madec, G.: Global Seasonal 970 forecast system version 5 (GloSea5): a high-resolution seasonal forecast system. Q.J.R. Meteorol. 971 Soc., 141: 1072-1084, 2015.

McLandress, C. and Shepherd, T.G.: Impact of climate change on stratospheric sudden warmings as 973 simulated by the Canadian Middle Atmosphere Model. J. Clim., 22, 5449-5463, 2009.

974 McLandress, C., Shepherd, T.G., Scinocca, J.F., Plummer, D.A., Sigmond, M., Jonsson, A.I. and 975 Reader, M.C.: Separating the dynamical effects of climate change and ozone depletion: Part 2.

976 Southern Hemisphere Troposphere. J. Clim., 24, 1850-1868, 2011.

Meehl G. et al.: Initialised Earth System Prediction from Subseasonal to Decadal Timescales. Nat.

978 Rev. Earth. Environ. 2, 340-357, 2021.

979 Merryfield, W.J., J. Baehr, L. Batté, E.J. Becker, A.H. Butler, et al., Current and emerging 980 developments in subseasonal to decadal prediction, BAMS, 101, E869-E896, 2020.

981 Merryfield, W. J., F. J. Doblas-Reyes, L. Ferranti, J.-H. Jeong, Y. J. Orsolini, R. I. Saurral, A. A. 982 Scaife, M. A. Tolstykh, and M. Rixen. Advancing climate forecasting. EOS, 98, 17-21, 2017. 
Molina, M., Rowland, F.: Stratospheric sink for chlorofluoromethanes: chlorine atom-catalysed destruction of ozone. Nature 249, 810-812, 1974. performance, impacts and future. Atmos. Chem. Phys. Disc., doi: 10.5194/acp-2020-1261, 2021. Müller, W. A., and Roeckner, E.: ENSO impact on midlatitude circulation patterns in future climate change projections, Geophys. Res. Lett., 33, L05711, 2006.

Mukougawa, H., Sakai, H., \& Hirooka, T.: High sensitivity to the initial condition for the prediction of stratospheric sudden warming. Geophysical Research Letters, 32, L17806, 2005. predictability of the tropospheric Northern Annular Mode, Geophys. Res. Lett., 36, L08814, doi:10.1029/2008GL037127, 2009. Arctic Oscillations. Env. Res. Lett., 14, 3, 2019.

Noguchi, S., Mukougawa, H., Kuroda, Y., Mizuta, R., Yabu, S., \& Yoshimura, H.: Predictability of the stratospheric polar vortex breakdown: An ensemble reforecast experiment for the splitting event in January 2009. Journal of Geophysical Research: Atmospheres, 121, 3388-3404, 2016.

1009 observations on forecasting sudden stratospheric warmings. Geophysical Research Letters, 47, 1010 e2019GL086233, 2020a.

1011 Noguchi, S., Kuroda, Y., Kodera, K., \& Watanabe, S.: Robust enhancement of tropical convective 1012 activity by the 2019 Antarctic sudden stratospheric warming. Geophysical Research Letters, 47, 1013 e2020GL088743, 2020b.

1014 Oehrlein J., G. Chiodo and L.M. Polvani: The effect of interactive ozone chemistry on weak and 1015 strong stratospheric polar vortex events, Atmos. Chem. Phys., 20, 10531-10544, 2020.

1016 Omrani, NE., Keenlyside, N.S., Bader, J. et al.: Stratosphere key for wintertime atmospheric response to warm Atlantic decadal conditions. Clim Dyn 42, 649-663, 2014.

1018 O'Reilly CH, Weisheimer A, Woollings T, Gray LJ, MacLeod D: The importance of stratospheric 1019 initial conditions for winter North Atlantic Oscillation predictability and implications for the signal1020 to-noise paradox. Q J R Meteorol Soc 145(718):131-146, 2019.

1021 Orsolini YJ, Senan R, Benestad RE, Melsom A. Autumn atmospheric response to the 2007 low Arctic 1022 sea ice extent in coupled ocean-atmosphere hindcasts. Clim Dyn 38:2437-2448, 2012.

1023 Owens, M.J., Mike Lockwood, Ed Hawkins, Ilya Usoskin, Gareth S. Jones, Luke Barnard, Andrew 1024 Schurer and John Fasullo: The Maunder minimum and the Little Ice Age: an update from recent 1025 reconstructions and climate simulations. J. Space Weather Space Clim., 7 (2017) A33, 2017.

1026 Pawson, S. and B. Naujokat: The cold winters of the middle 1990s in the northern lower stratosphere. 1027 J. Geophys. Res., 104, 14 209-14 222, 1999.

1028 Pawson, S., Kodera, K., Hamilton, K., Shepherd, T. G., Beagley, S. R., Boville, B. A., Farrara, J. D., 1029 Fairlie, T. D. A., Kitoh, A., Lahoz, W. A., Langematz, U., Manzini, E., Rind, D. H., Scaife, A. A., 1030 Shibata, K., Simon, P., Swinbank, R., Takacs, L., Wilson, R. J., Al-Saadi, J. A., Amodei, M., Chiba, 

D., Lerner, J., Mahlman, J. D., McFarlane, N. A., Mechoso, C. R., Molod, A., O'Neill, A., Pierce, R. B., Randel, W. J., Rood, R. B., \& Wu, F.: The GCM-Reality Intercomparison Project for SPARC

1034 (GRIPS): Scientific Issues and Initial Results, Bulletin of the American Meteorological Society, 81(4), 1035 781-796, 2000.

1036 Peings, Y. E. Brun, V. Mauvais, H. Douville: How stationary is the relationship between Siberian 1037 snow and Arctic Oscillation over the 20th century? Geophys. Res. Lett., 40, 183-188, 2013.

1038 Perlwitz, J., and N. Harnik: Observational evidence of a stratospheric influence on the troposphere by 1039 planetary wave reflection, J. Clim., 16, 3011-3026, 2003.

1040 Perlwitz, J., \& Graf, H.: The Statistical Connection between Tropospheric and Stratospheric

1041 Circulation of the Northern Hemisphere in Winter, Journal of Climate, 8(10), 2281-2295, 1995.

1042 Plumb, R. A., and Semeniuk, K.: Downward migration of extratropical zonal wind anomalies, J.

1043 Geophys. Res., 108, 4223, doi:10.1029/2002JD002773, D7, 2003.

1044 Polvani L.M. and P.J. Kushner: Tropospheric response to stratospheric perturbations in a relatively

1045 simple general circulation model, Geophys. Res. Lett., 29, no. 7 (2002) Liu C., B. Tian, K.-F. Li, G.L.

1046 Manney, N.J. Livesey, Y.L. Yung, D.E. Waliser. Northern Hemisphere mid-winter vortex-

1047 displacement and vortex-split stratospheric sudden warmings: influence of the Madden-Julian

1048 Oscillation and Quasi-Biennial Oscillation. J. Geophys. Res. Atmos., 119, 12,599-12,620, 2014.

1049 Polvani, L.M., D.W. Waugh, G.J.P. Correa and S.-W. Son: Stratospheric ozone depletion: the main 1050 driver of 20th Century atmospheric circulation changes in the Southern Hemisphere, J. Climate, 24, $1051795-812,2011$.

1052 Polvani L.M., L. Sun, A.H. Butler, J.H. Richter and C. Deser: Distinguishing stratospheric sudden 1053 warmings from ENSO as key drivers of wintertime climate variability over the North Atlantic and 1054 Eurasia, J. Clim., 30, 1959-1969, 2017.

1055 Polvani, L. M., and Kushner, P. J., Tropospheric response to stratospheric perturbations in a relatively 1056 simple general circulation model, Geophys. Res. Lett., 29(7), doi:10.1029/2001GL014284, 2002.

1057 Polvani, L.M., L. Sun, A.H. Butler, J.H. Richter and C. Deser: Distinguishing stratospheric sudden 1058 warmings from ENSO as key drivers of wintertime climate variability over the North Atlantic and 1059 Eurasia, J. Climate, 30, 1959-1969, 2017.

1060 Previdi, M. and L.M. Polvani: Climate System Response to Stratospheric Ozone Depletion and 1061 Recovery, Quart. J. Roy. Meteor. Soc., 140, 2401-2419, 2014.

1062 Purich, A., and S.-W. Son: Impact of Antarctic ozone depletion and recovery on Southern Hemisphere 1063 precipitation, evaporation and extreme changes, Journal of Climate, 25, 3145-3154, 2012.

1064 Rao, J., C. I. Garfinkel, and I. P. White: Predicting the downward and surface influence of the 1065 February 2018 and January 2019 sudden stratospheric warming events in subseasonal to seasonal 1066 (S2S) models, Journal of Geophysical Research: Atmospheres, 125, 2020a

1067 Rao, J., C. I. Garfinkel, I. P. White, C. Schwartz: How does the Quasi-Biennial Oscillation affect the 1068 boreal winter tropospheric circulation in CMIP5/6 models?, Journal of Climate, 33, 8975-8996, $10692020 b$.

1070 Rao, J. and C. I. Garfinkel: CMIP5/6 Models Project Little Change in the Statistical Characteristics of 1071 Sudden Stratospheric Warmings in the 21st Century, Environmental Research Letters, 2020c. 
1072

1073

1074

1075

1076

1077

1078

1079

1080

1081

1082

1083

1084

1085

1086

1087

1088

1089

1090

1091

1092

1093

1094

1095

1096

1097

1098

1099

1100

1101

1102

1103

1104

1105

1106

1107

1108

1109

1110

1111

1112

1113

1114
Rao, J., C. I. Garfinkel, and I. P. White: Projected strengthening of the extratropical surface impacts of the stratospheric Quasi Biennial Oscillation, Geophysical Research Letters, 47, e2020GL089149, 2020d.

Rao, J., C. I. Garfinkel, I. P. White, C. Schwartz: The Southern Hemisphere Minor Sudden Stratospheric Warming in September 2019 and its predictions in S2S Models, Journal of Geophysical Research: Atmospheres, 125, e2020JD032723, doi:10.1029/2020JD032723, 2020e.

Rao, J. and Garfinkel, C.I.: The Strong Stratospheric Polar Vortex in March 2020 in Sub-Seasonal to Seasonal Models: Implications for Empirical Prediction of the Low Arctic Total Ozone Extreme. Journal of Geophysical Research: Atmospheres, 126(9), p.e2020JD034190., 2021a.

Rao, J., Garfinkel, C. I., \& White, I. P.: Development of the Extratropical Response to the Stratospheric Quasi-Biennial Oscillation, Journal of Climate (published online ahead of print), $2021 \mathrm{~b}$.

Reichler, T., Kim, J., Manzini, E., \& Kröger, J.: A stratospheric connection to Atlantic climate variability. Nature Geoscience, 5(11), 783-787, 2012.

Richter, J. H., Pegion, K., Sun, L., Kim, H., Caron, J. M., Glanville, A., LaJoie, E., Yeager, S., Kim, W. M., Tawfik, A., \& Collins, D.: Subseasonal Prediction with and without a Well-Represented Stratosphere in CESM1, Weather and Forecasting, 35(6), 2589-2602, 2020a.

Richter, J. H., Anstey, J. A., Butchart, N., Kawatani, Y., Meehl, G. A., Osprey, S., \& Simpson, I. R.: Progress in simulating the quasi-biennial oscillation in CMIP models. Journal Geophysical Research: Atmospheres, 125, e2019JD032362, 2020 b.

Richter, JH, Butchart, N, Kawatani, Y, et al.: Response of the Quasi-Biennial Oscillation to a warming climate in global climate models. Q J R Meteorol Soc.; 1- 29, 2020c.

Riddle, E.E., A.H. Butler, J.C. Furtado, J.L. Cohen, and A. Kumar, CFSv2 ensemble prediction of the wintertime Arctic Oscillation, Climate Dynamics, 41, 1099-1116, 2013.

Rind, D., Suozzo, R., Balachandran, N. K., Lacis, A., \& Russell, G.. The GISS global climate-middle atmosphere model. Part I: Model structure and climatology. Journal of the Atmospheric Sciences, 45, 329-370, 1988.

Roff, G., D. W. J. Thompson, and H. Hendon: Does increasing model stratospheric resolution improve extended-range forecast skill? Geophys. Res. Lett., 38, L05809, 2011.

Runde, T., Dameris, M., Garny, H., \& Kinnison, D. E.: Classification of stratospheric extreme events according to their downward propagation to the troposphere. Geophysical Research Letters, 43(12), 6665-6672, 2016.

Saito, N., Maeda, S., Nakaegawa, T., Takaya, Y., Imada, Y., \& Matsukawa C.: Seasonal predictability of the North Atlantic Oscillation and zonal mean fields associated with stratospheric influence in JMA/MRI-CPS2. Scientific Online Letters on the Atmosphere, 13, 209-213, 2017.

Samarasinghe, S. M., Connolly, C., Barnes, E. A., Ebert-Uphoff, I., \& Sun, L.: Strengthened causal connections between the MJO and the North Atlantic with climate warming. Geophysical Research Letters, 48, e2020GL091168, 2021.

Sassi, F., Garcia, R. R., Boville, B. A., and Liu, H.: On temperature inversions and the mesospheric surf zone, J. Geophys. Res., 107( D19), 4380, 2002.

Scaife A.A., T. Spangehl, D. Fereday, U. Cubasch, U. Langematz, H. Akiyoshi, S. Bekki, P. Braesicke, N. Butchart, M. Chipperfield, A. Gettelman, S. Hardiman, M. Michou, E. Rozanov and T.G. Shepherd. Climate Change and Stratosphere-Troposphere Interaction. Clim. Dyn., 38, Page 2089-2097, 2012. 
Scaife A.A., N. Butchart, C.D. Warner, D. Stainforth, W.A. Norton and J. Austin. Realistic QuasiBiennial Oscillations in a simulation of the global climate. Geophys. Res. Let. 27, 3481-3484, 2000.

Scaife A.A., J.R. Knight, G.K. Vallis, C.K. Folland. A stratospheric influence on the winter NAO and North Atlantic surface climate. Geophys. Res. Let., 32, L18715, 2005.

Scaife A.A. and J.R. Knight. Ensemble simulations of the cold European winter of 2005/6. Q. J. R. Meteorol. Soc., 134, 1647-1659, 2008.

Scaife A.A., C.K. Folland, L. Alexander, A. Moberg and J.R. Knight: European climate extremes and the North Atlantic Oscillation. J. Clim., 21, 72-83, 2008.

Scaife, A. A., et al.: Predictability of the quasi-biennial oscillation and its northern winter teleconnection on seasonal to decadal timescales, Geophys. Res. Lett., 41, 1752-1758, 2014a.

Scaife, A. A., et al.: Skillful long-range prediction of European and North American winters, Geophys. Res. Lett., 41, 2514- 2519, 2014 b.

Scaife A.A., A.-Yu. Karpechko, M.P. Baldwin, A. Brookshaw, A.H. Butler, R. Eade, M. Gordon, C. MacLachlan, N. Martin, N. Dunstone and D. Smith: Seasonal winter forecasts and the stratosphere. Atm. Sci. Lett., 2016.

Schwartz, C. and C.I. Garfinkel: Relative Roles of the MJO and Stratospheric Variability in North Atlantic and European Winter Climate . J. Geoph. Res, doi: 10.1002/2016JD025829, 2017.

Schwartz, C. and C.I. Garfinkel: Troposphere-stratosphere coupling in subseasonal-to-seasonal models and its importance for a realistic extratropical response to the Madden-Julian Oscillation. Journal of Geophysical Research: Atmospheres, 125(10), p.e2019JD032043, 2020.

Screen, J.A., Deser, C., Smith, D.M. et al.: Consistency and discrepancy in the atmospheric response to Arctic sea-ice loss across climate models. Nature Geosci 11, 155-163, 2018.

Screen, J. A. and Blackport, R.: How robust is the atmospheric response to projected Arctic sea ice loss across climate models?. Geophysical Research Letters, 46, 11406- 11415, 2019.

Seviour, W. J. M., S. C. Hardiman, L. J. Gray, N. Butchart, C. MacLachlan, and A. A. Scaife: Skillful seasonal prediction of the Southern Annular Mode and Antarctic ozone. J. Clim., 27, 7462-7474, doi:10.1175/JCLI-D-14-00264.1, 2014.

Shukla, J.: Dynamical Predictability of Monthly Means. J. Atmos. Sci., 38(12), 2547-2572, 1981.

Shindell, D. T., Schmidt, G. A., Miller, R. L., and Rind, D.: Northern hemisphere winter climate response to greenhouse gas, ozone, solar, and volcanic forcing, J. Geophys. Res., 106( D7), 7193$7210,2001$.

Sigmond, M., Scinocca, J.F., Kharin, V.V. and Shepherd, T.G.. Enhanced seasonal forecast skill following stratospheric sudden warmings. Nature Geosci., 6, 98-102, 2013.

Simpson, I. R., Hitchcock, P., Seager, R., Wu, Y., \& Callaghan, P.: The Downward Influence of Uncertainty in the Northern Hemisphere Stratospheric Polar Vortex Response to Climate Change. Journal of Climate, 31(16), 6371-6391., 2018.

Sigmond, M., J. F. Scinocca and P. J. Kushner: The impact of the stratosphere on tropospheric climate change. Geophys. Res. Lett., 35, L12706, 2008.

Sigmond, M. and J.F. Scinocca: The influence of basic state on the Northern Hemisphere circulation response to climate change. J. Clim., 23, 1434-1446, , 2010.

Sigmond M., Scinocca J.F., Kharin V.V., Shephgerd T.G.. Enhanced seasonal forecast skill following stratospheric sudden warmings. Nature Geoscience, 6, 98-102, 2013. 
Shaw T.A. and J. Perlwitz. The life cycle of Northern Hemisphere downward wave coupling between the stratosphere and troposphere. J. Clim., 26, 1745-1763, 2013

Smith K.L. and L M Polvani. The surface impacts of Arctic stratospheric ozone anomalies. Environ. Res. Lett. $9074015,2014$.

Solomon, S., Ivy, D. J., Kinnison, D., Mills, M. J., Neely, R. R., \& Schmidt, A.: Emergence of healing in the Antarctic ozone layer. Science, 353(6296), 269-274, 2016.

Son, S.W. , L.M. Polvani, D.W. Waugh and CCMVal co-authors: The impact of stratospheric ozone recovery on the Southern Hemisphere westerly jet, Science, 320, 1486-1489, 2008.

Son, S.-W., Purich, A., Hendon, H. H., Kim, B.-M., and Polvani, L. M.: Improved seasonal forecast using ozone hole variability?, Geophys. Res. Lett., 40, 6231- 6235, 2013.

Son, S-W., Y. Lim, C. Yoo, H. H. Hendon, and J. Kim: Stratospheric control of Madden-Julian Oscillation, Journal of Climate, 30, 1909-1922, 2017.

Son. S-W, B-R. Han, C.I. Garfinkel, and 26 others: Tropospheric jet response to Antarctic ozone depletion: An update with Chemistry-Climate Model Initiative (CCMI) models, Environmental Research Letters, 13, 054024, 2018.

Son, S.-W., H. Kim, K. Song, S.-W. Kim, P. Martineau, Y.-K. Hyun, and Y. Kim: Extratropical prediction skill of the subseasonal-to-seasonal (S2S) prediction models, Journal of Geophysical Research - Atmosphere, 125, e2019JD031273, 2020.

Song, K. and Son, S.: Revisiting the ENSO-SSW Relationship, Journal of Climate, 31(6), 2133-2143, 2018.

Statnaia, I., A. Yu. Karpechko, H. Järvinen: Mechanisms and predictability of Sudden Stratospheric Warming in winter 2018, Weather and Climate Dynamics, 2020.

Steil, B., Dameris, M., Brühl, C. et al.: Development of a chemistry module for GCMs: first results of a multiannual integration. Annales Geophysicae 16, 205-228, 1998.

Stenchikov, G., Hamilton, K., Stouffer, R. J., Robock, A., Ramaswamy, V., Santer, B., and Graf, H.F.: Arctic Oscillation response to volcanic eruptions in the IPCC AR4 climate models, J. Geophys. Res., 111, D07107, 2006.

Stockdale, T. N., Molteni, F. and Ferranti, L. (2015), Atmospheric initial conditions and the predictability of the Arctic Oscillation. Geophys. Res. Lett., 42: 1173-1179. doi: 10.1002/2014GL062681.

Stockdale et al.: Multi-Model Predictions of the Quasi-Biennial Oscillation. Quart. J. Roy. Met. Soc., in press, 2021.

Sun, L., Deser, C., \& Tomas, R. A.: Mechanisms of Stratospheric and Tropospheric Circulation Response to Projected Arctic Sea Ice Loss, Journal of Climate, 28(19), 7824-7845, 2015.

Swinbank, R., Douglas, C.S., Lahoz, W.A., O'neill, A. and Heaps, A.: Middle atmosphere variability in the UK Meteorological Office Unified Model. Q.J.R. Meteorol. Soc., 124: 1485-1525, 1998.

Swingedouw, D., Pablo Ortega, Juliette Mignot, Eric Guilyardi, Valérie Masson-Delmotte, Paul G. Butler, Myriam Khodri, Roland Séférian: Bidecadal North Atlantic ocean circulation variability controlled by timing of volcanic eruptions. Nature Communications, 2015; 6: 6545, 2015.

Taguchi, M.: Seasonal Winter forecasts of the northern stratosphere and troposphere: Results from JMA seasonal hindcast experiments. Journal of the Atmospheric Sciences, 75 (3), 827-840, 2018. 

Operational 1-Month Ensemble Predictions from 2001/02 to 2012/13, Journal of the Atmospheric Sciences, 73(2), 789-806, 2016.

Takaya, Y., T. Yasuda, Y. Fujii, S. Matsumoto, T. Soga, H. Mori, M. Hirai, I. Ishikawa, H. Sato, A. Shimpo, M. Kamachi, T. Ose: Japan Meteorological Agency/Meteorological Research InstituteCoupled Prediction System version 1 (JMA/MRI-CPS1) for operational seasonal forecasting, Clim.

1204 Dyn.,1-2, 313-333, 2017.

1205

Thiéblemont, R., Matthes, K., Omrani, NE. et al.: Solar forcing synchronizes decadal North Atlantic climate variability. Nat. Comm. 6, 8268, 2015.

Thompson, D.W.J., Susan Solomon: Interpretation of Recent Southern Hemisphere Climate Change. Science, 296, Issue 5569, pp. 895-899, 2002.

Thompson, D.W.J., M.P. Baldwin, and J. M. Wallace: Stratospheric connection to Northern Hemisphere wintertime weather: Implications for prediction. J. Climate, 15, 1421-1428, 2002.

Thompson, D. W. J., M. P. Baldwin, and S. Solomon: Stratosphere-troposphere coupling in the Southern Hemisphere. J. Atmos. Sci., 62, 708-715, 2005.

Thompson, D., Solomon, S., Kushner, P. et al.: Signatures of the Antarctic ozone hole in Southern Hemisphere surface climate change. Nature Geosci 4, 741-749 (2011).

Tompkins, A. M., Ortiz De Zárate, M. I., Saurral, R. I., Vera, C., Saulo, C., Merryfield, W. J., Sigmond, M., Lee, W., Baehr, J., Braun, A., Butler, A., Déqué, M., Doblas-Reyes, F. J., Gordon, M., Scaife, A. A., Imada, Y., Ishii, M., Ose, T., Kirtman, B., Kumar, A., Müller, W. A., Pirani, A., Stockdale, T., Rixen, M., \& Yasuda, T.: The Climate-System Historical Forecast Project: Providing Open Access to Seasonal Forecast Ensembles from Centers around the Globe, Bulletin of the American Meteorological Society, 98(11), 2293-2301, 2017.

Tripathi, O.P., M. Baldwin, A. Charlton-Perez, M. Charron, S. Eckermann, E. Gerber, G. Harrison, D. Jackson, B. Kim, Y. Kuroda, A. Lang, C. Lee, S. Mahmood, R. Mizuta, G. Roff, M. Sigmond, S-W. Son: The predictability of the extra-tropical stratosphere on monthly timescales and its impact on the skill of tropospheric forecasts, Q. J. R. Meteorol. Soc., 141, 987-1003, $2015 \mathrm{a}$.

Tripathi, O., Charlton-Perez, A., Sigmond, M., and Vitart, F: Enhanced long-range forecast skill in boreal winter following stratospheric strong vortex conditions. Environ. Res. Lett. 10, 104007, 2015b

Tyrrell, N. L., A. Yu. Karpechko and P. Raisanen: The Influence of Eurasian Snow Extent on the Northern Extratropical Stratosphere in a QBO Resolving Model, J. Geophys. Res., 123, 1, 315-328, 2018.

Tyrrell N. L., Karpechko A. Y., Uotila P., Vihma T.: Atmospheric circulation response to anomalous Siberian forcing in October 2016 and its long-range predictability. Geophys. Res. Lett., 46, 2800$2810,2019$.

Tyrrell, N., A. Yu. Karpechko and S. Rast: Siberian snow forcing in a dynamically bias-corrected model, J. Climate, v. 33, 10455-10467, 2020.

Vitart, F.: Madden-Julian Oscillation prediction and teleconnections in the S2S database. Q.J.R. Meteorol. Soc, 143: 2210-2220, 2017.

Wang, L., Ting, M. \& Kushner, P.J.: A robust empirical seasonal prediction of winter NAO and surface climate. Sci Rep 7, 279, 2017.

Wang L. et al.: What chance of a sudden stratospheric warming in the southern hemisphere? Environ. Res. Lett., 15, 104038, 2020. 
Warner, J. L., Screen, J. A., \& Scaife, A. A.: Links between Barents-Kara sea ice and the extratropical atmospheric circulation explained by internal variability and tropical forcing. Geophysical Research Letters, 47, e2019GL085679, 2020.

1244 White, I., C. I. Garfinkel, E. P. Gerber, M. Jucker, P. Hitchcock, and J. Rao: The generic nature of the tropospheric response to sudden stratospheric warmings, Journal of Climate, 33, 5589-5610, 2020.

1246 Wittman, L.M. Polvani, R.K. Scott and A.J. Charlton: Stratospheric influence on baroclinic lifecycles and its connection to the Arctic Oscillation, Geophys. Res. Lett., 31, L16113, 2004.

1248 Wittman, A.J. Charlton and L.M. Polvani: The effect of lower stratospheric shear on baroclinic 1249 instability, J. Atmos. Sci., 64, 479-496, 2007.

1250 Woo, SH., Sung, MK., Son, SW. et al.: Connection between weak stratospheric vortex events and the 1251 Pacific Decadal Oscillation. Clim Dyn 45, 3481-3492 (2015).

1252 Yamazaki, K., Nakamura, T., Ukita, J., and Hoshi, K.: A tropospheric pathway of the stratospheric 1253 quasi-biennial oscillation (QBO) impact on the boreal winter polar vortex, Atmos. Chem. Phys., 20, 1254 5111-5127, 2020.

1255 Yoo, C., and Son, S.-W.: Modulation of the boreal wintertime Madden-Julian oscillation by the 1256 stratospheric quasi-biennial oscillation, Geophys. Res. Lett., 43, 1392- 1398, 2016.

1257 Zappa, G. and Shepherd, T.G.: Storylines of atmospheric circulation change for European regional 1258 climate impact assessment. J. Clim., 30, 6561-6577, 2017.

1259 Zappa, G., Pithan, F. and Shepherd, T.G.: Multimodel evidence for an atmospheric circulation 1260 response to Arctic sea ice loss in the CMIP5 future projections. Geophys. Res. Lett., 45, 1011-1019, 12612018.

1262 Zhang, F., Sun, Y. Q., Magnusson, L., Buizza, R., Lin, S., Chen, J., \& Emanuel, K.: What Is the 1263 Predictability Limit of Midlatitude Weather?, J. Atm. Sci., 76(4), 1077-1091, 2019.

1264 Zhang, P., Wu, Y., Simpson, I. R., Smith, K. L., Zhang, X., De, B., \& Callaghan, P.: A stratospheric 1265 pathway linking a colder Siberia to Barents-Kara Sea sea ice loss. Science Advances, 4(7), eaat6025, 12662018. 